\title{
Determination of the Effect of Coal/Biomass-Derived Syngas Contaminants on the Performance of Fischer-Tropsch and Water-Gas-Shift Catalysts
}

\section{Final Report}

Reporting Period:

October 1, 2008 to December 31, 2010

By

Jason P. Trembly, Matthew E. Cooper, Justin Farmer, Brian S. Turk, and Raghubir P. Gupta 


\section{Disclaimer}

This report was prepared as an account of work sponsored by an agency of the U.S. Government. Neither the U.S. Government nor any agency thereof, nor any of its employees, makes any warranty, express or implied, or assumes any legal liability or responsibility for the accuracy, completeness, or usefulness of any information, apparatus, product, or process disclosed, or represents that its use would not infringe privately owned rights. Reference herein to any specific commercial product, process, or service by trade name, trademark, manufacturer, or otherwise does not necessarily constitute or imply its endorsement, recommendation, or favoring by the U.S. Government or any agency thereof. The views and opinions of the authors expressed therein do not necessarily state or reflect those of the U.S. Government or any agency thereof. 


\section{Acknowledgements}

This project was sponsored by the National Energy Technology Laboratory (NETL) of the U.S. Department of Energy (DOE), under Contract No. DE-NT0006479. This financial assistance from DOE/NETL is gratefully acknowledged. In addition, the major cost-sharing for this project was provided by Süd-Chemie, Inc. (SCI) and RTI International. Recognition of contributing individuals from these organizations is provided below.

DOE/NETL: Elaine Everitt, Daniel Driscoll, and Daniel Cicero.

Süd-Chemie Inc.: Troy Walsh, Tom Pusty, and Jeff Braden.

RTI International: Engineering and Analytical Support: Gary Howe, Martin Lee, and David Coker. Technical Support: Ernie Johnson. Financial Support: Teri Williams and Evan Picard. Administrative Support: Yvonne Harrison and Deanna Penick. 


\section{Table of Contents}

\section{Chapter}

Page

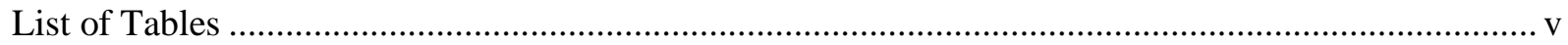

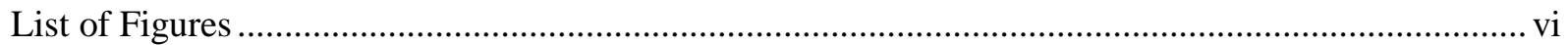

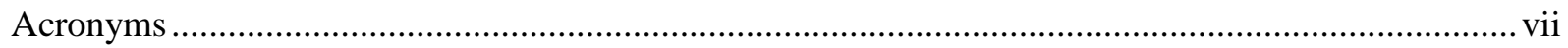

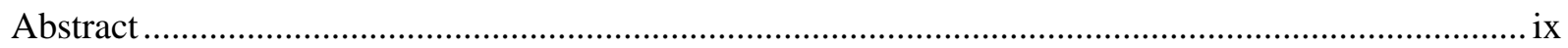

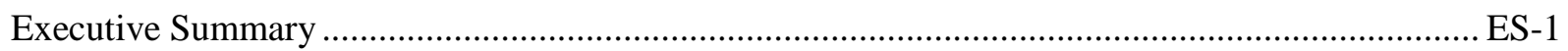

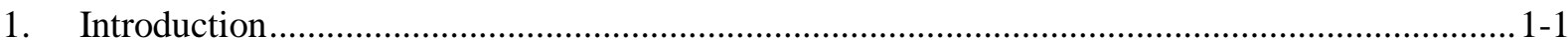

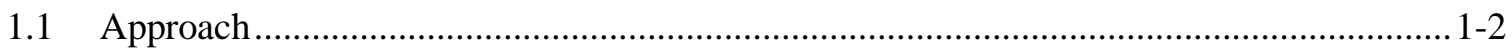

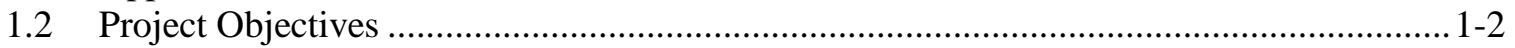

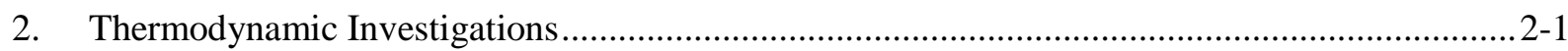

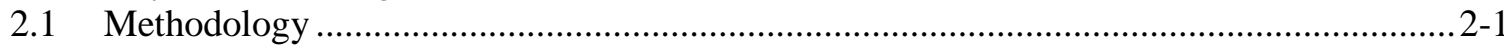

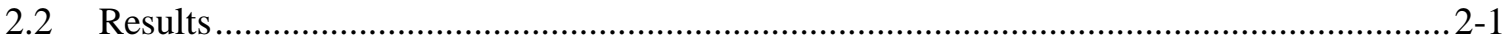

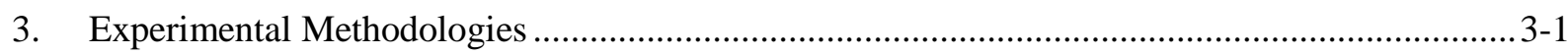

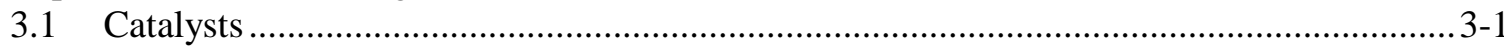

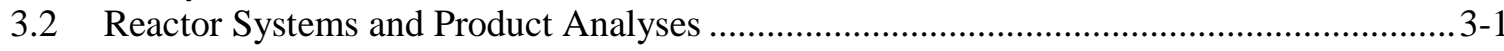

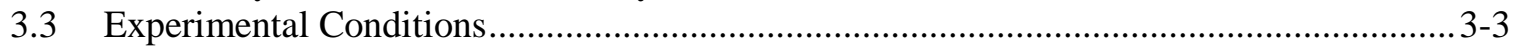

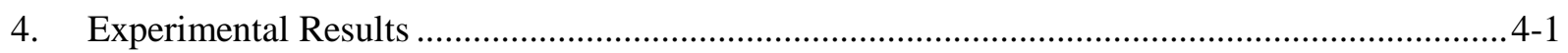

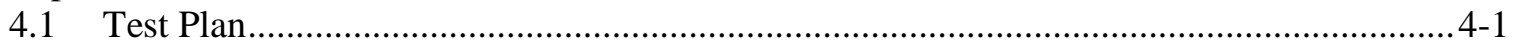

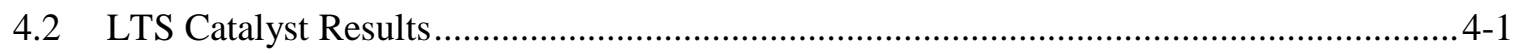

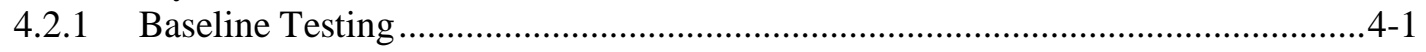

4.2.2 Multi-contaminant Exposure .................................................................. $4-2$

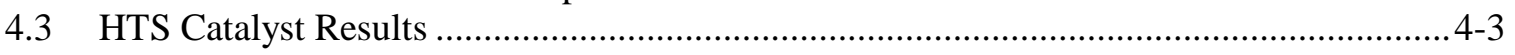

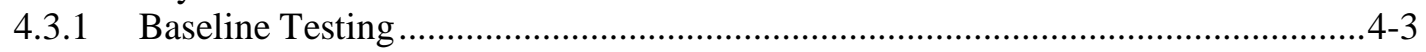

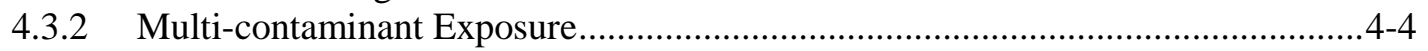

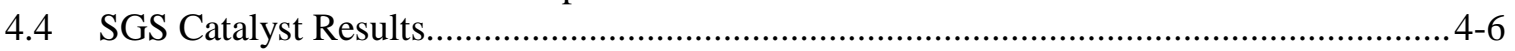

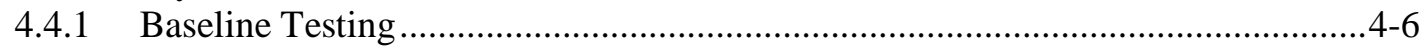

4.4.2 Multi-contaminant Exposure ...........................................................................

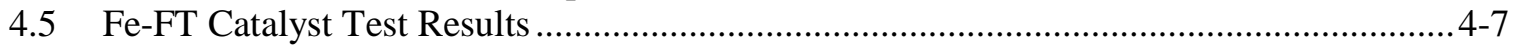

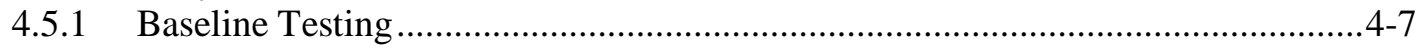

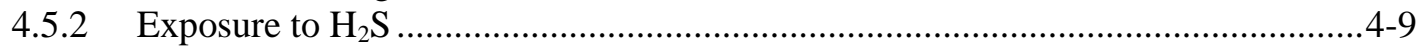

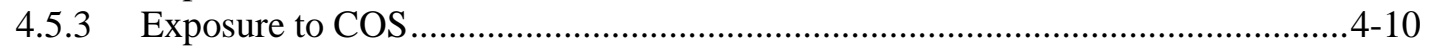

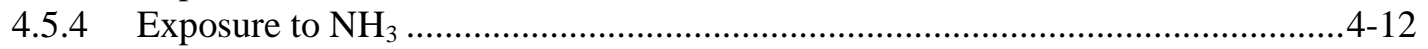

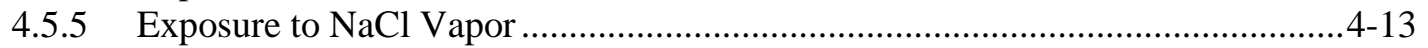

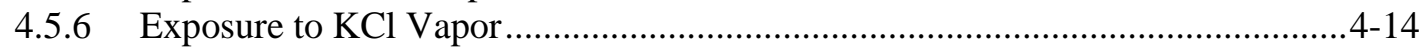

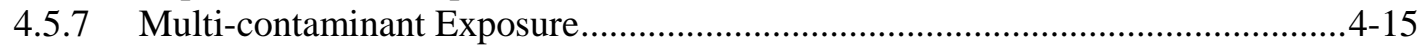

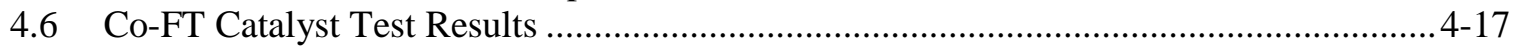

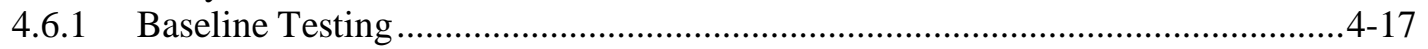




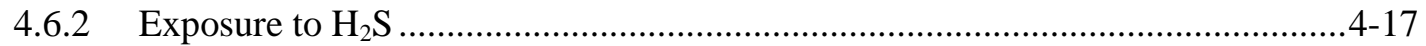

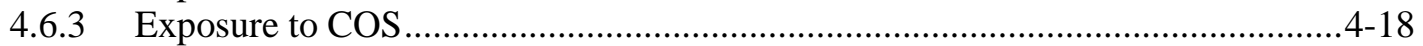

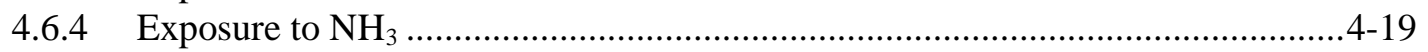

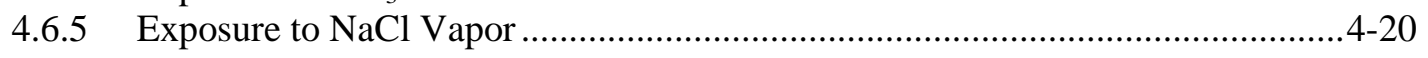

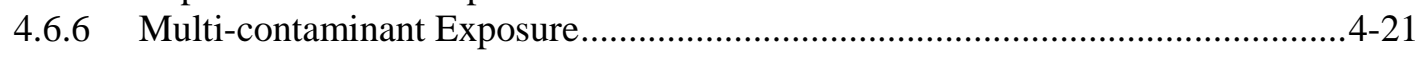

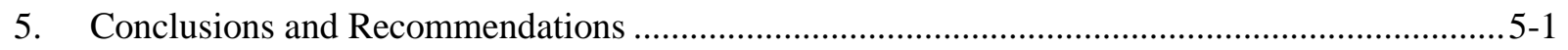




\section{List of Tables}

Number

Table ES-1. Summary of Changes in Catalyst Performance during Contaminant Exposure Trials

Table 2-1. Potential Interactions between WGS Catalyst Components and Trace Species Present in CB-Derived Syngas

Table 2-2. Potential Interactions between FT Catalyst Components and Trace Species Present in CB-Derived Syngas .

Table 3-1. WGS and FT Catalyst Formulations …...............................................................

Table 3-2. Baseline WGS and FT System Test Parameters ....................................................... 3-4

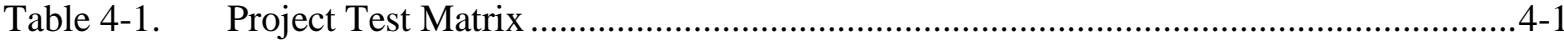

Table 4-2. Concentrations of Alkali Vapors during Testing with Simulated CB-Derived Syngas

Table 4-3. $\quad$ LTS Catalyst Performance during Multi-contaminant Testing ..................................4-3

Table 4-4. HTS Catalyst Performance during Multi-contaminant Testing ..................................4-5

Table 4-5. SGS Catalyst Performance during Multi-contaminant Testing ..................................4-7

Table 4-6. Baseline Fe-FT Catalyst Performance and Selectivities.............................................4-8

Table 4-7. Effect of $\mathrm{H}_{2} \mathrm{~S}$ Concentration on Fe-FT Catalyst Performance ...................................4-10

Table 4-8. Effect of COS Concentration on Fe-FT Catalyst Performance ..................................4-12

Table 4-9. Effect of $\mathrm{NH}_{3}$ Concentration on Fe-FT Catalyst Performance …............................... $4-13$

Table 4-10. Fe-FT Catalyst Performance Results in the Presence of $\mathrm{NaCl}$ Vapor ........................4-14

Table 4-11. Fe-FT Catalyst Performance Results in the Presence of $\mathrm{KCl}$ Vapor .........................4-15

Table 4-12. Fe-FT Catalyst Performance during Multi-contaminant Testing .............................4-16

Table 4-13. Effect of COS Concentration on Co-FT Catalyst Performance ..................................4-19

Table 4-14. Effect of $\mathrm{NH}_{3}$ Concentration on Co-FT Catalyst Performance .................................4-20

Table 4-15. Co-FT Catalyst Performance Results in the Presence of $\mathrm{NaCl}$ Vapor........................4-21

Table 4-16. Co-FT Catalyst Performance during Multi-contaminant Testing ..............................4-22

Table 5-1. Summary of Results from Contaminant Exposure Trials ..........................................5-1 


\section{List of Figures}

\section{Number}

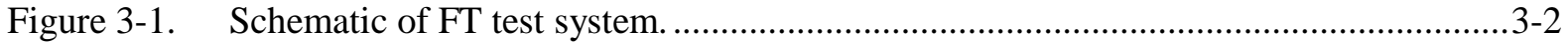

Figure 3-2. Laboratory-scale microreactor systems a) WGS and b) FT. .....................................3-2

Figure 4-1. Baseline test results for the LTS catalyst..................................................................4-2

Figure 4-2. Multi-contaminant exposure results for the LTS catalyst..........................................4-3

Figure 4-3. Baseline test results for the HTS catalyst. ................................................................4-4

Figure 4-4. CO conversion of the HTS catalyst in the presence of syngas containing multiple contaminants

Figure 4-5. Baseline test results for the SGS catalyst. ............................................................

Figure 4-6. CO conversion of the SGS catalyst in multi-contaminant exposure testing................4-7

Figure 4-7. Baseline test results for the Fe-FT catalyst............................................................. $4-8$

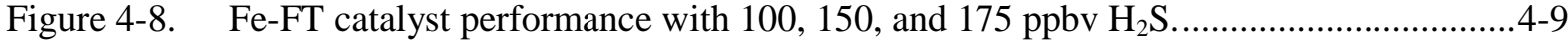

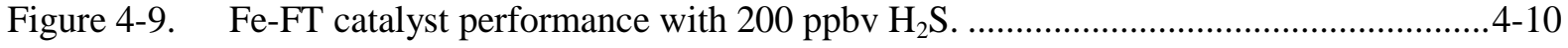

Figure 4-10. Fe-FT catalyst performance with 125 and 175 ppbv COS in syngas. .......................4-11

Figure 4-11. Fe-FT catalyst performance with 150 and 200 ppbv COS. ....................................4-11

Figure 4-12. Fe-FT catalyst performance with 100, 500, and 1,000 ppbv $\mathrm{NH}_{3} \ldots \ldots \ldots \ldots \ldots \ldots \ldots \ldots . . . . . . . . . . . . .13$

Figure 4-13. Effect of $\mathrm{NaCl}$ vapor on $\mathrm{Fe}-\mathrm{FT}$ catalyst performance. …........................................4-14

Figure 4-14. CO conversion and FT wax $\alpha$ of the Fe-FT catalyst with syngas containing $\mathrm{KCl}$ vapor.

Figure 4-15. CO conversion and FT wax $\alpha$ of the Fe-FT catalyst with syngas containing multiple trace components.

Figure 4-16. Baseline performance of the commercial Co-FT catalyst. ......................................4-17

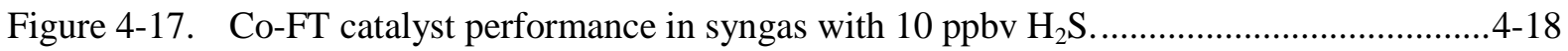

Figure 4-18. Co-FT catalyst performance with 10, 40, and 100 ppbv COS in syngas...................4-19

Figure 4-19. CO conversion and FT wax $\alpha$ for the Co-FT catalyst with syngas containing varying $\mathrm{NH}_{3}$ concentrations

Figure 4-20. Effect of $\mathrm{NaCl}$ vapor in syngas on $\mathrm{CO}$ conversion and FT wax $\alpha$ of the Co-FT catalyst.

Figure 4-21. CO conversion and FT wax $\alpha$ of the Co-FT catalyst with syngas containing multi-contaminants. 


\section{Acronyms}

$\alpha$

$\mathrm{Al}_{2} \mathrm{O}_{3}$

$\mathrm{NH}_{4}$

$\mathrm{Sb}$

Ar

As

$\mathrm{AsH}_{3}$

$\mathrm{C}_{1}$

$\mathrm{C}_{7}$

$\mathrm{C}_{\text {frac,i }}$

$\mathrm{Cd}$

$\mathrm{CO}$

$\mathrm{CO}_{2}$

$\mathrm{COS}$

${ }^{\circ} \mathrm{C}$

$\mathrm{Cr}_{2} \mathrm{O}_{3}$

CB

CBTL

Co

Co-FT

$\mathrm{CuO}$

$\mathrm{Cc}$

$\Delta \mathrm{G}_{\mathrm{rxn}}$

DOE

$\mathrm{Eq}$

FT

GC

HTS

$\mathrm{H}_{2}$

$\mathrm{HCl}$

$\mathrm{H}_{2} \mathrm{Se}$

$\mathrm{H}_{2} \mathrm{~S}$

In.

ID

$\mathrm{Fe}$

$\mathrm{Fe}-\mathrm{FT}$

$\mathrm{Fe}_{2} \mathrm{O}_{3}$

$\mathrm{K}$

$\mathrm{kJ} / \mathrm{mol}$

LTS

$\mathrm{MgO}$

$\mu \mathrm{m}$

$\mathrm{mg} \mathrm{C}_{5} / \mathrm{h} / \mathrm{g}$ catalyst catalyst

$\mathrm{Hg}$

$\mathrm{CH}_{4}$ alpha and represents the probability of chain growth

Alumina

Ammonia

Antimony

Argon

Arsenic

Arsine

Molecular species with 1 carbon atom

Molecular species with 7 carbon atoms

Weight fraction of product with i carbon atoms

Cadmium

Carbon monoxide

Carbon dioxide

Carbonyl sulfide

Degrees Celsius

Chromium oxide

Coal/biomass

coal/biomass-to-liquids

Cobalt

Cobalt-based Fischer-Tropsch

Copper oxide

cubic centimeters

Gibbs free energy of reaction

Department of Energy

Equation

Fischer-Tropsch

Gas chromatograph

High temperature shift

Hydrogen

Hydrogen chloride

Hydrogen selenide

Hydrogen sulfide

Inches

Internal diameter

Iron

Iron-based Fischer-Tropsch

Iron oxide

Constant in Anderson-Schulz-Flory probability distribution equation

kilojoules per mole

Low temperature shift

Magnesium oxide

microns

$\mathrm{Mg}$ of molecular species with 5 or more carbon atoms per hour per gram of

Mercury

Methane 


$\begin{array}{ll}\mathrm{MoO}_{3} & \text { Molybdenum oxide } \\ \mathrm{N}_{\mathrm{i}} & \text { Number of carbon atoms } \\ \mathrm{NETL} & \text { National Energy Technology Laboratory } \\ \mathrm{ND} & \text { Not detected } \\ \mathrm{N} / \mathrm{A} & \text { Not available } \\ \mathrm{NO}_{\mathrm{x}} & \text { Oxides of nitrogen } \\ \mathrm{Ppmv} & \text { Parts per million by volume } \\ \mathrm{Ppbv} & \text { Parts per billion by volume } \\ \mathrm{Pptv} & \text { Parts per trillion by volume } \\ \mathrm{P} & \text { Phosphorus } \\ \mathrm{PH}_{3} & \text { Phosphine } \\ \mathrm{K} & \text { Potassium } \\ \mathrm{K}_{2} \mathrm{CO} & \text { Potassium carbonate } \\ \mathrm{KCl} & \text { Potassium chloride } \\ \mathrm{R \& D} & \text { Research and development } \\ \mathrm{RuO} & \text { Ruthenium oxide } \\ \mathrm{Se} & \text { Selenium } \\ \mathrm{SiO} & \text { Silicon dioxide } \\ \mathrm{Na} & \text { Sodium } \\ \mathrm{NaCl} & \text { Sodium chloride } \\ \mathrm{SGS} & \text { Sour gas shift } \\ \mathrm{SO} & \text { Oxides of sulfur } \\ \mathrm{SPB}-1 & \text { Trademark name for GC column manufactured by Sigma Aldrich } \\ \mathrm{SNG} & \text { Substitute natural gas } \\ \mathrm{SCI} & \text { Süd-Chemie, Inc. } \\ 24 / 7 & \text { 24 hours a day and 7 days a week } \\ \mathrm{U} . \mathrm{S} . & \text { United States of America } \\ \mathrm{WGS} & \text { Water gas shift } \\ \mathrm{ZnO} & \text { Zinc oxide } \\ & \end{array}$




\section{Abstract}

Today, nearly all liquid fuels and commodity chemicals are produced from non-renewable resources such as crude oil and natural gas. Because of increasing scrutiny of carbon dioxide $\left(\mathrm{CO}_{2}\right)$ emissions produced using traditional fossil-fuel resources, the utilization of alternative feedstocks for the production of power, hydrogen, value-added chemicals, and high-quality hydrocarbon fuels such as diesel and substitute natural gas (SNG) is critical to meeting the rapidly growing energy needs of modern society. Coal and biomass are particularly attractive as alternative feedstocks because of the abundant reserves of these resources worldwide. The strategy of co-gasification of coal/biomass (CB) mixtures to produce syngas for synthesis of Fischer-Tropsch (FT) fuels offers distinct advantages over gasification of either coal or biomass alone. Co-feeding coal with biomass offers the opportunity to exploit economies of scale that are difficult to achieve in biomass gasification, while the addition of biomass to the coal gasifier feed leverages proven coal gasification technology and allows $\mathrm{CO}_{2}$ credit benefits.

Syngas generated from CB mixtures will have a unique contaminant composition because coal and biomass possess different concentrations and types of contaminants, and the final syngas composition is also strongly influenced by the gasification technology used. Syngas cleanup for gasification of CB mixtures will need to address this unique contaminant composition to support downstream processing and equipment.

To investigate the impact of CB gasification on the production of transportation fuels by FT synthesis, RTI International conducted thermodynamic studies to identify trace contaminants that will react with water-gas-shift and FT catalysts and built several automated microreactor systems to investigate the effect of single components and the synergistic effects of multiple contaminants on water-gas-shift and FT catalyst performance. The contaminants investigated were sodium chloride $(\mathrm{NaCl})$, potassium chloride $(\mathrm{KCl})$, hydrogen sulfide $\left(\mathrm{H}_{2} \mathrm{~S}\right)$, carbonyl sulfide $(\mathrm{COS})$, ammonia $\left(\mathrm{NH}_{3}\right)$, and combinations thereof. This report details the thermodynamic studies and the individual and multi-contaminant results from this testing program. 


\section{Executive Summary}

The overall objective of this project was to quantify the effects of syngas contaminants generated during entrained-flow gasification of coal/biomass (CB) mixtures on commercial water-gas-shift (WGS) and Fischer-Tropsch (FT) catalysts.

The project approach was to test actual commercial WGS and FT catalysts with simulated syngas containing contaminants specific to CB-derived syngas to quantify

- Changes in catalyst activity and selectivity

- Changes in catalyst physical/chemical properties

- Catalyst changes resulting from simultaneous interaction with multiple contaminants

- Effects of contaminant concentration on catalyst changes

Commercial samples of high-temperature-shift (HTS) catalyst, low-temperature-shift (LTS) catalyst, sour-gas-shift (SGS) catalyst, and cobalt (Co)- and iron (Fe)-based FT catalysts provided by Süd-Chemie Inc. (SCI) were evaluated in the studies.

To determine which trace contaminants present in CB-derived syngas could potentially react with the catalysts, a series of thermodynamic analyses in which the catalysts were represented by their chemical components (active catalyst, binder, support, etc.) were completed. These analyses showed that catalyst components could potentially react with a host of trace contaminants, in particular, with arsenic (As), phosphorous (P), and selenium (Se) identified as the contaminants having the most favored potential for reaction. Based on the thermodynamic analysis results, the contaminants recommended for experimental testing included sulfur (hydrogen sulfide $\left(\mathrm{H}_{2} \mathrm{~S}\right)$ and carbonyl sulfide $(\mathrm{COS})$, ammonia $\left(\mathrm{NH}_{3}\right)$, alkalis, hydrogen chloride $(\mathrm{HCl})$, arsine $\left(\mathrm{AsH}_{3}\right)$, hydrogen selenide $\left(\mathrm{H}_{2} \mathrm{Se}\right)$, phosphine $\left(\mathrm{PH}_{3}\right)$, and mercury $(\mathrm{Hg})$. In this project, the commercial WGS and FT catalysts were tested with only a subset of these contaminants, specifically $\mathrm{H}_{2} \mathrm{~S}, \mathrm{COS}, \mathrm{NH}_{3}$, sodium chloride $(\mathrm{NaCl})$, and potassium chloride $(\mathrm{KCl})$, and combinations of these contaminants. Selection of these contaminants and the range of contaminant concentrations used during the test were based on most accurately representing syngas produced by gasification of $\mathrm{CB}$ mixtures and potential for catalyst poisoning.

To efficiently evaluate performance of the commercial catalysts, a series of automated microreactor systems were designed, fabricated, and operated to effectively expose each catalyst to simulated CB-derived syngas containing known amounts of contaminants for up to 1,000 continuous hours of testing. The catalyst testing was performed at temperature and pressure conditions typically used in commercial catalyst operation. During testing, the effluent products (gas and waxes) were analyzed by gas chromatograph (GC) to monitor catalyst performance (catalyst activity and selectivity).

The baseline performance for each catalyst was established by conducting an initial trial in which the catalyst was exposed to a simulated CB syngas mixture containing no contaminants. After stable catalyst performance was achieved, introduction of the contaminants was started. The exposure trials for the WGS catalysts focused on multi-contaminant exposure. For the FT catalysts, the exposure trials focused on initial testing with single contaminants followed by testing with multiple contaminants. A summary of these exposure trial results is provided in Table ES-1. In general, the most significant adverse effect on catalyst performance was seen with the sulfur species $\left(\mathrm{H}_{2} \mathrm{~S}\right.$ and $\left.\mathrm{COS}\right) . \mathrm{H}_{2} \mathrm{~S}$ was also observed to be a stronger catalyst poison than COS. The catalyst most sensitive to contaminants was the Co-FT catalyst. 
Table ES-1. Summary of Changes in Catalyst Performance during Contaminant Exposure Trials

\begin{tabular}{|c|c|c|}
\hline \multirow{2}{*}{ Catalyst } & \multicolumn{2}{|c|}{ Exposure trial } \\
\hline & Individual contaminants ${ }^{1}$ & Multiple contaminants \\
\hline LTS & & $\begin{array}{l}\text { - No impact observed up to } 1,000 \text { parts per million } \\
\text { by volume (ppbv) of } \mathrm{NH}_{3} \text { and } \mathrm{H}_{2} \mathrm{~S}\end{array}$ \\
\hline HTS & & $\begin{array}{l}\text { Decline in carbon monoxide (CO) conversion } \\
\text { demonstrated for combinations of } \geq 150 \text { ppbv } \mathrm{H}_{2} \mathrm{~S} \\
\text { and } 1,000 \text { ppbv of } \mathrm{NH}_{3} \text { with alkali vapors } \\
\text { - Alkali vapors did not result in CO conversion } \\
\text { decline and potentially resulted in recovery of lost } \\
\text { CO conversion after exposure to } 1,000 \text { ppbv } \mathrm{H}_{2} \mathrm{~S}\end{array}$ \\
\hline SGS $^{2}$ & & - No impact observed up to $1,000 \mathrm{ppbv} \mathrm{NH}_{3}$ \\
\hline Fe-FT & $\begin{array}{l}\text { - } \mathrm{H}_{2} \mathrm{~S}: \text { Performance loss at }>150 \mathrm{ppbv} \\
\text { - } \mathrm{COS} \text { : Performance loss at }>175 \mathrm{ppbv} \\
\text { - } \mathrm{NaCl} \text { vapor: No impact } \\
\text { - } \mathrm{KCl} \text { vapor: No impact } \\
\text { - } \mathrm{NH}_{3} \text { : No impact } \\
\end{array}$ & $\begin{array}{l}\text { - Most significant decrease in } \mathrm{CO} \text { conversion } \\
\text { observed with } \mathrm{NaCl}, \mathrm{KCl} \text {, and } 100 \mathrm{ppbv}_{2} \mathrm{~S}\end{array}$ \\
\hline Co-FT & $\begin{array}{l}\text { - } \mathrm{H}_{2} \mathrm{~S}: \text { Performance loss at } 10 \mathrm{ppbv} \\
\text { - } \mathrm{COS} \text { : Performance loss at }>100 \mathrm{ppbv} \\
\text { - } \mathrm{NaCl} \text { vapor: No impact } \\
\text { - } \mathrm{NH}_{3} \text { : Performance loss at }>1,000 \mathrm{ppbv}\end{array}$ & $\begin{array}{l}\text { - Statistically significant decrease in } \mathrm{CO} \text { conversion } \\
\text { observed with } \mathrm{NaCl}, \mathrm{KCl}, 10 \text { ppbv } \mathrm{H}_{2} \mathrm{~S} \text {, and } 100 \\
\text { ppbv } \mathrm{NH}_{3}\end{array}$ \\
\hline
\end{tabular}

${ }^{1}$ Hatched regions indicate that individual contaminant exposure trials were not conducted with WGS catalysts.

${ }^{2}$ Multi-contaminant exposure trials were focused on alkali vapors and $\mathrm{NH}_{3}$.

The results discussed in this report are an invaluable contribution to a comprehensive database documenting catalyst performance during operation with contaminant-laden syngas. Such a database will eventually be used to establish syngas contaminant specifications for WGS and FT applications. 


\section{Introduction}

Today, nearly all liquid fuels and commodity chemicals are produced from non-renewable resources such as crude oil and natural gas. Because of increasing scrutiny of carbon dioxide $\left(\mathrm{CO}_{2}\right)$ emissions produced using traditional fossil-fuel resources, the utilization of alternative feedstocks for the production of power, hydrogen, value-added chemicals, and high-quality hydrocarbon fuels such as diesel and substitute natural gas (SNG) is critical to meeting the rapidly growing energy needs of modern society. Coal and biomass are particularly attractive as alternative feedstocks because the United States has abundant domestic reserves of these resources available. Research and development (R\&D) of technologies focused on the production of liquid fuels and SNG from coal/biomass (CB) mixtures via gasification was supported by the "Alternate Production Pathway" under the Hydrogen and Clean Fuels Program sponsored by the U.S. Department of Energy's (DOE's) National Energy Technology Laboratory (NETL). This R\&D program is particularly timely for:

- Providing a means to reduce the U.S. dependence on imported oil by using domestic coal and biomass energy resources;

- Reducing the $\mathrm{CO}_{2}$ footprint of fuel and chemical production by using coal/biomass-to-liquids (CBTL) processes that, when integrated with carbon capture or reuse, have lower $\mathrm{CO}_{2}$ emissions than conventional petroleum-fuel-based processes;

- Creating a near-zero footprint for other emissions, including $\mathrm{SO}_{\mathrm{x}}, \mathrm{NO}_{\mathrm{x}}$, and mercury;

- Increasing energy sustainability by optimizing the integration of renewable biomass utilization in fuel production; and

- Facilitating commercial deployment of the most effective gasification technologies available.

Economic projections indicate that coal-biomass-to-liquid (CBTL) processes should be cost-competitive at oil prices significantly below the current price of $\$ 80$ per barrel of crude oil. However, the process assumptions used to generate these economic projections need to be validated and/or optimized for realistic operating conditions. One important assumption pertains to the performance and lifetime of commercial catalysts to be used in the water-gas-shift (WGS) and Fischer-Tropsch (FT) synthesis processes in CBTL production. Because commercial WGS and FT catalysts are very sensitive to poisoning by trace contaminants present in the process gas streams, the economic projections are based on critical assumptions about the catalyst replacement cost and the capital cost for syngas cleaning processes needed to achieve a target catalyst life expectancy. An optimal balance of these two costs is required to provide the most cost-competitive CBTL process, and determination of this optimal cost balance requires

- Identification of the CB-derived syngas contaminants that are poisons for WGS and FT catalysts; and

- Knowledge of the effect of contaminant concentrations on the rates of catalyst degradation and deactivation.

For syngas generated from conventional commercial feedstocks such as natural gas, poisons for WGS and FT catalysts have been identified. Moreover, these conventional feedstocks are not used in their raw ("dirty") material state because they typically undergo multiple refining operations before being introduced into WGS and FT processes. As a result, the "refined" feedstocks usually have only one or two contaminants that could act as catalyst poisons.

In contrast, a significantly larger number of contaminants, especially at low or trace concentrations, are found in syngas generated from alternative feedstocks such as coal, biomass, or mixtures of coal and 
biomass. Thus, there is an increase in the probability of catalyst poisoning not only by single contaminants but also by simultaneous, synergistic interactions of multiple contaminants. In addition to catalyst deactivation through activity loss, the contaminants could adversely affect catalyst support and binder components, leading to undesirable physical changes that further shorten catalyst lifetime. This report provides results from studies evaluating long-term catalyst performance impacts for hydrogen sulfide $\left(\mathrm{H}_{2} \mathrm{~S}\right)$, carbonyl sulfide $(\mathrm{COS})$, ammonia $\left(\mathrm{NH}_{3}\right)$, potassium chloride $(\mathrm{KCl})$, and sodium chloride $(\mathrm{NaCl})$ in syngas, with the goal of increasing the knowledge base to be eventually used in defining/establishing contaminant specifications for WGS and FT catalysts and syngas cleanup processes.

\subsection{Approach}

The approach for this project was to test commercial WGS and FT catalysts with simulated syngas containing contaminants specific to CB-derived syngas to quantify

- Changes in catalyst activity and selectivity;

- Changes in catalyst physical/chemical properties;

- Catalyst changes resulting from simultaneous interaction with multiple contaminants; and

- Effects of contaminant concentration on catalyst changes.

Commercial samples of high-temperature-shift (HTS), low-temperature-shift (LTS), sour-gas-shift (SGS), cobalt-based FT (Co-FT), and iron-based FT (Fe-FT) catalysts were provided by Süd-Chemie Inc. (SCI). The specific contaminants evaluated in this project were $\mathrm{H}_{2} \mathrm{~S}, \mathrm{COS}, \mathrm{NH}_{3}, \mathrm{NaCl}$, and $\mathrm{KCl}$. Catalyst testing was performed at temperature and pressure conditions typically used in commercial catalyst operation. Microreactor systems designed to operate 24/7 with limited supervision were used to expose each catalyst to simulated CB-derived syngas containing known amounts of contaminants for up to 1,000 continuous hours of testing. During testing, the effluent products (gas and waxes) were analyzed by gas chromatograph (GC) to monitor catalyst performance (catalyst activity and selectivity). The length of the tests was sufficient to establish catalyst changes resulting from contaminants.

\subsection{Project Objectives}

The project objective was to quantify the effects of syngas contaminants generated during entrained-flow gasification of CB mixtures on commercial WGS and FT catalysts. The specific contaminant effects quantified were

- Changes in catalyst activity and selectivity;

- Changes in catalyst physical/chemical properties;

- Catalyst changes resulting from simultaneous interaction with multiple contaminants; and

- Effects of contaminant concentration on catalyst changes.

The scope of the project work involved thermodynamic evaluation of potential interactions between catalyst components (active catalyst, binder, support, etc.) and CB-derived syngas contaminants, development of specialized automated testing systems, and evaluation of commercial WGS and FT catalyst performance with simulated CB-derived syngas containing specific contaminants. 


\section{Thermodynamic Investigations}

\section{$2.1 \quad$ Methodology}

To supplement the catalyst testing in this project, a thermodynamic study was used to evaluate potential interactions between contaminants present in CB-derived syngas and commercial FT and WGS catalysts at typical operating conditions. The study results provided educated guidance for selecting suitable contaminant testing levels by helping identify potential reaction mechanisms for changes in catalyst physical properties and performance associated with specific contaminants.

The thermo-chemistry software package HSC Chemistry (v. 5.1) was used to calculate the concentration of different species present at thermodynamic equilibrium conditions. The roster of contaminant species present in CB-derived syngas was developed from U.S. Department of Energy reports, as well as published data on syngas compositions associated with different entrained-flow gasification systems. This contaminant list included antimony $(\mathrm{Sb})$, arsine $\left(\mathrm{AsH}_{3}\right)$, hydrogen chloride $(\mathrm{HCl})$, cadmium $(\mathrm{Cd})$, $\mathrm{COS}, \mathrm{H}_{2} \mathrm{~S}$, mercury $(\mathrm{Hg})$, phosphine $\left(\mathrm{PH}_{3}\right)$, selenium $(\mathrm{Se})$, potassium $(\mathrm{K})$, and sodium $(\mathrm{Na})$. The specific chemical components/species in the commercial HTS, LTS, HTS, SGS, Fe-FT, and Co-FT catalyst formulations investigated were obtained from available technical/marketing information in SCI's and Haldor Topsoe's marketing brochures and websites.

\subsection{Results}

Potential interactions between trace contaminants and catalyst components (active catalyst, binder, support, etc.) were determined by their thermodynamic probability to form a chemical compound with each other based on a Gibbs Free Energy analysis. This thermodynamic probability was divided into three categories: (i) not favored $\left(\Delta \mathrm{G}_{\mathrm{rxn}}>0 \mathrm{~kJ} / \mathrm{mol}\right)$, (ii) slightly favored $\left(-100 \mathrm{~kJ} / \mathrm{mol}<\Delta \mathrm{G}_{\mathrm{rxn}}<0\right.$ $\mathrm{kJ} / \mathrm{mol}$ ), and (iii) strongly favored $\left(\Delta \mathrm{G}_{\mathrm{rxn}}<-100 \mathrm{~kJ} / \mathrm{mol}\right)$. Tables $2-1$ and $2-2$ summarize the thermodynamic probability results for the WGS and FT catalysts, respectively. The rows in these tables show the thermodynamic reaction probability for contaminants, and the columns present the thermodynamic reaction probability for catalyst components. Hence, the intersection of a particular row and column provides the thermodynamic probability of forming a stable chemical compound between the indicated specific contaminant and catalyst component.

As indicated in Tables 2-1 and 2-2, several contaminants are strongly favored thermodynamically to react with WGS and FT catalyst components. The contaminants with the most favored potential for interactions are arsenic (As), phosphorus (P), and Se. Although little reactivity is predicted for $\mathrm{Hg}$, amalgam formation was not included in this thermodynamic analysis. Based on the thermodynamic study, the contaminants recommended for experimental testing included sulfur $\left(\mathrm{H}_{2} \mathrm{~S}\right.$ and $\left.\mathrm{COS}\right)$, alkalis, $\mathrm{HCl}, \mathrm{AsH}_{3}, \mathrm{H}_{2} \mathrm{Se}, \mathrm{PH}_{3}$, and $\mathrm{Hg}$. In this project, however, only a subset of these contaminants, specifically $\mathrm{H}_{2} \mathrm{~S}, \mathrm{COS}, \mathrm{NH}_{3}, \mathrm{NaCl}$, and $\mathrm{KCl}$, was selected for testing the commercial WGS and FT catalysts. The specific subset of contaminants chosen were based the results from the thermodynamic studies, the unique contaminant mixtures resulting from gasification of $\mathrm{CB}$ mixtures, and DOE's programmatic goals. 
Table 2-1. Potential Interactions between WGS Catalyst Components and Trace Species Present in CB-Derived Syngas

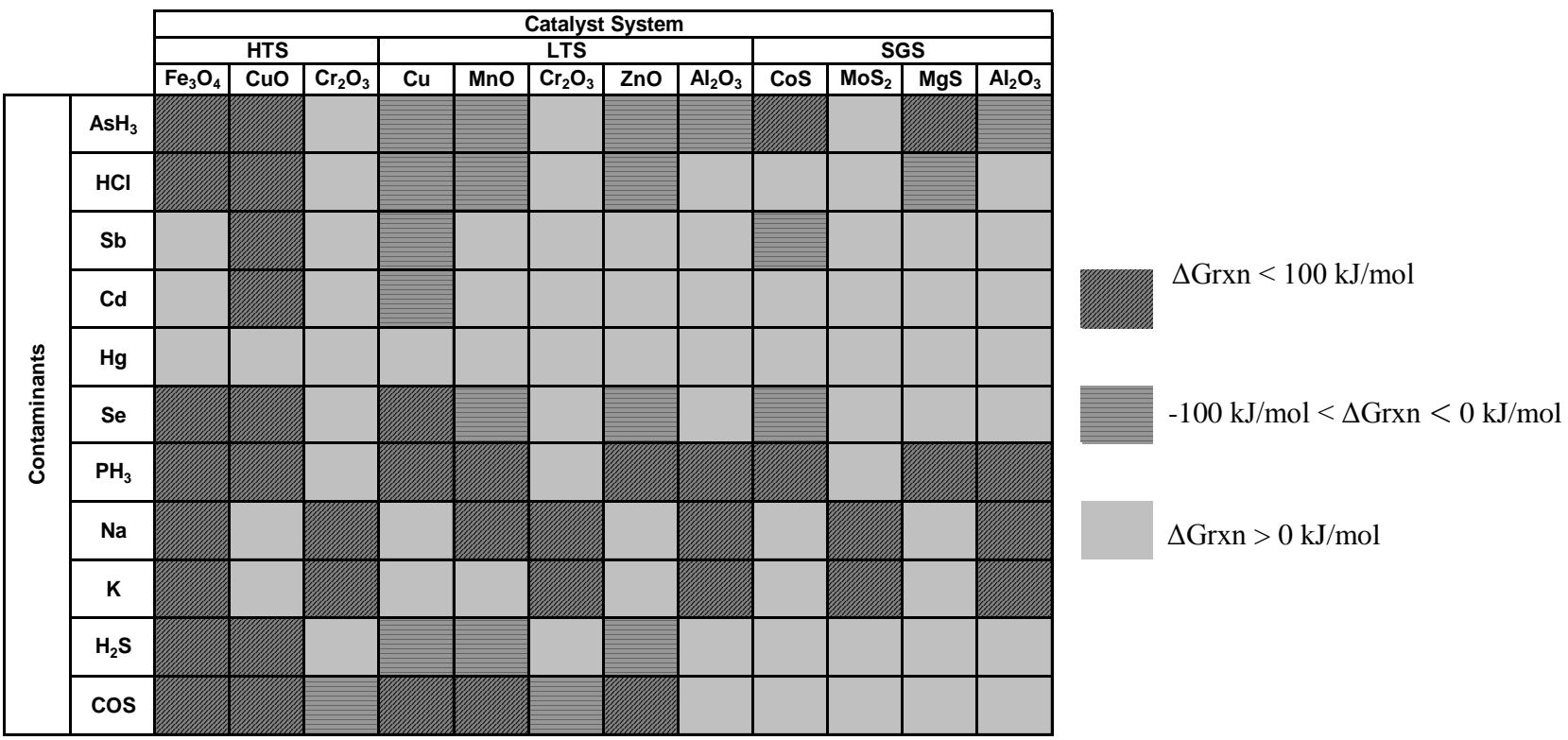

Table 2-2. Potential Interactions between FT Catalyst Components and Trace Species Present in CB-Derived Syngas

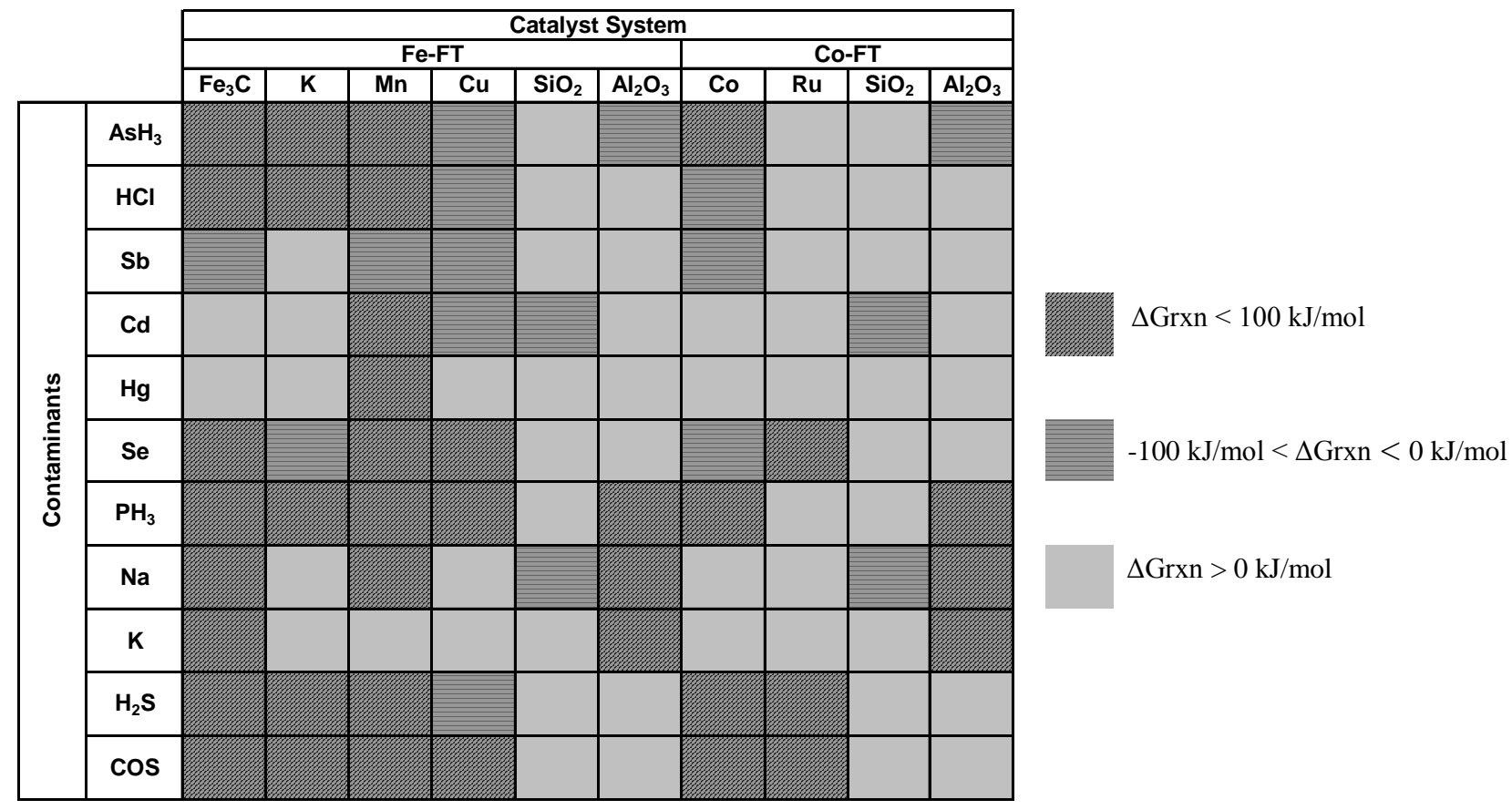




\section{Experimental Methodologies}

\subsection{Catalysts}

To provide industrially relevant information to WGS and FT end users, RTI International partnered with SCI, a commercial manufacturer and provider of WGS and FT catalysts. For the tests in this project, SCI supplied commercially available WGS and Co-FT catalysts and a commercially prepared standard Fe-FT catalyst. The formulations of these WGS and FT catalysts are given in Table 3-1.

Table 3-1. WGS and FT Catalyst Formulations

\begin{tabular}{|c|c|c|}
\hline Catalyst & Trade Name & Composition [wt\%] \\
\hline $\begin{array}{l}\text { LTS } \\
\text { (Low-temperature-shift) }\end{array}$ & ShiftMax $240^{\circledR}$ & $\begin{array}{l}59.0 \% \mathrm{CuO} \\
30.5 \% \mathrm{ZnO} \\
10.5 \% \mathrm{Al}_{2} \mathrm{O}_{3}\end{array}$ \\
\hline $\begin{array}{l}\text { HTS } \\
\text { (High-temperature- } \\
\text { shift) }\end{array}$ & ShiftMax $120^{\circledR}$ & $\begin{array}{c}89.5 \% \mathrm{Fe}_{2} \mathrm{O}_{3} \\
8.5 \% \mathrm{Cr}_{2} \mathrm{O}_{3} \\
2.0 \% \mathrm{CuO}\end{array}$ \\
\hline $\begin{array}{l}\text { SGS } \\
\text { (Sour-gas-shift) }\end{array}$ & ShiftMax $820^{\circledR}$ & $\begin{array}{c}10.0 \% \mathrm{MoO}_{3} \\
4.0 \% \mathrm{CoO} \\
18.0 \% \mathrm{MgO} \\
68.0 \% \mathrm{Al}_{2} \mathrm{O}_{3} \\
\end{array}$ \\
\hline $\begin{array}{l}\text { Fe-FT } \\
\text { (Iron-based } \\
\text { Fischer-Tropsch) }\end{array}$ & RTI-6 & $\begin{array}{c}84.3 \% \mathrm{Fe}_{2} \mathrm{O}_{3} \\
3.7 \% \mathrm{CuO} \\
2.0 \% \mathrm{~K}_{2} \mathrm{CO}_{3} \\
10.0 \% \mathrm{SiO}_{2}\end{array}$ \\
\hline $\begin{array}{l}\text { Co-FT } \\
\text { (Cobalt-based } \\
\text { Fischer-Tropsch) }\end{array}$ & FTMAX $^{\circledR}$ & $\begin{array}{c}24.10 \% \mathrm{CoO} \\
0.16 \% \mathrm{RuO} \\
75.74 \% \mathrm{Al}_{2} \mathrm{O}_{3}\end{array}$ \\
\hline
\end{tabular}

Except for the Fe-FT catalyst, which was supplied as a powder, all catalysts supplied by SCI were in pelletized form. To prepare for testing, the pelletized catalysts were first crushed using a mortar and pestle and then sieved to collect particles in the size range of 53 to $104 \mu \mathrm{m}$. This particle size range was chosen to minimize gas channeling in the interparticle spaces within the catalyst bed and to allow for effective separation of catalyst from the inert $\alpha$-alumina diluent in post-trial catalyst characterization. The particle size of the $\alpha$-alumina used in the trials was larger than $125 \mu \mathrm{m}$.

\subsection{Reactor Systems and Product Analyses}

The performance of the WGS and FT catalysts was determined in laboratory-scale microreactor systems. A dedicated laboratory-scale microreactor system was constructed for each of the five catalysts tested. A schematic for the FT test system is shown in Figure 3-1. Photos of the microreactor systems are shown in Figure 3-2. The downflow fixed-bed reactor in these test systems consisted of a $0.37 \mathrm{in}$. ID stainless steel tube that contained a nominal 2 cc of catalyst diluted $3: 1$ by volume with $\alpha$-alumina to dissipate exothermic heat of reaction during testing. The reactor was heated with band heaters (Watlow) controlled by a thermocouple placed inside a thermowell in the catalyst bed. Mass flow controllers (Brooks 5850i) 


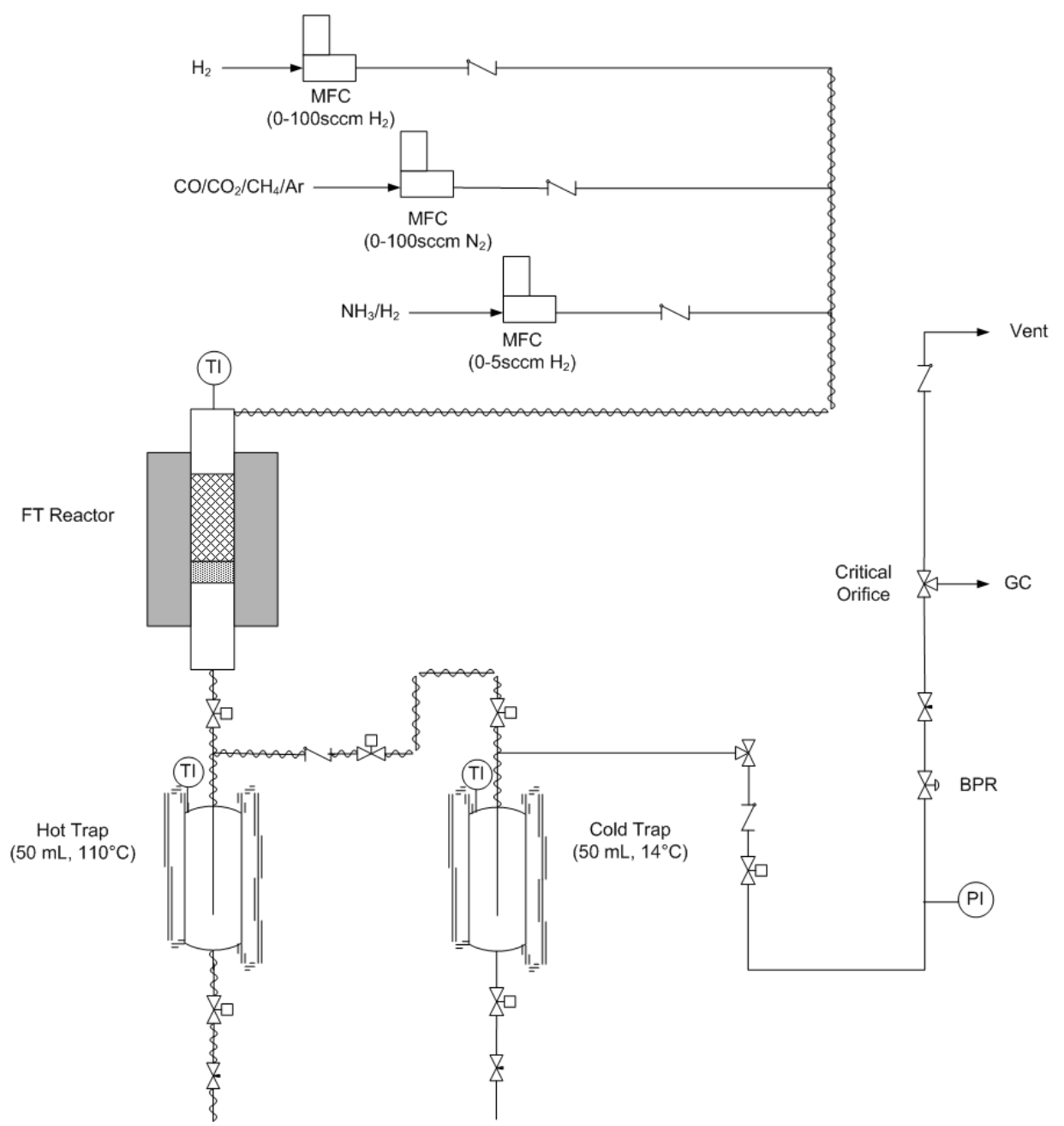

Figure 3-1. Schematic of FT test system.

a)

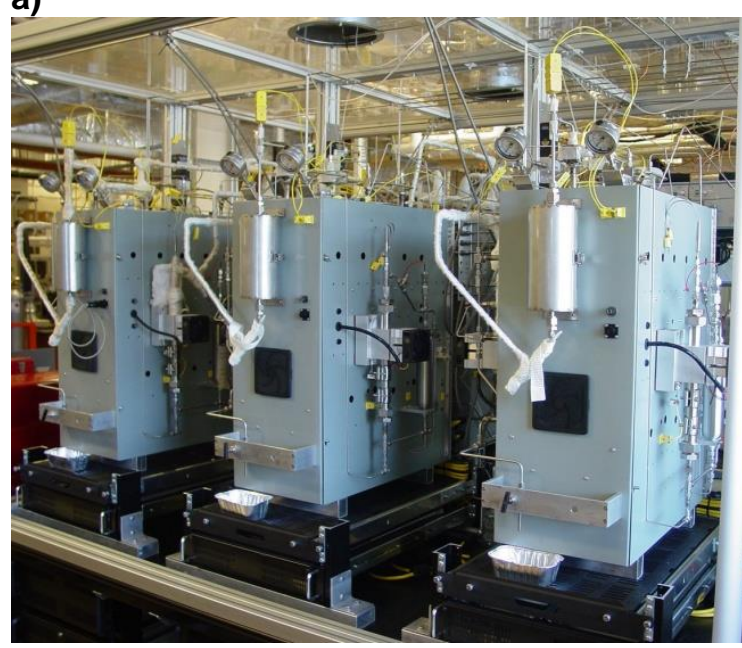

b)

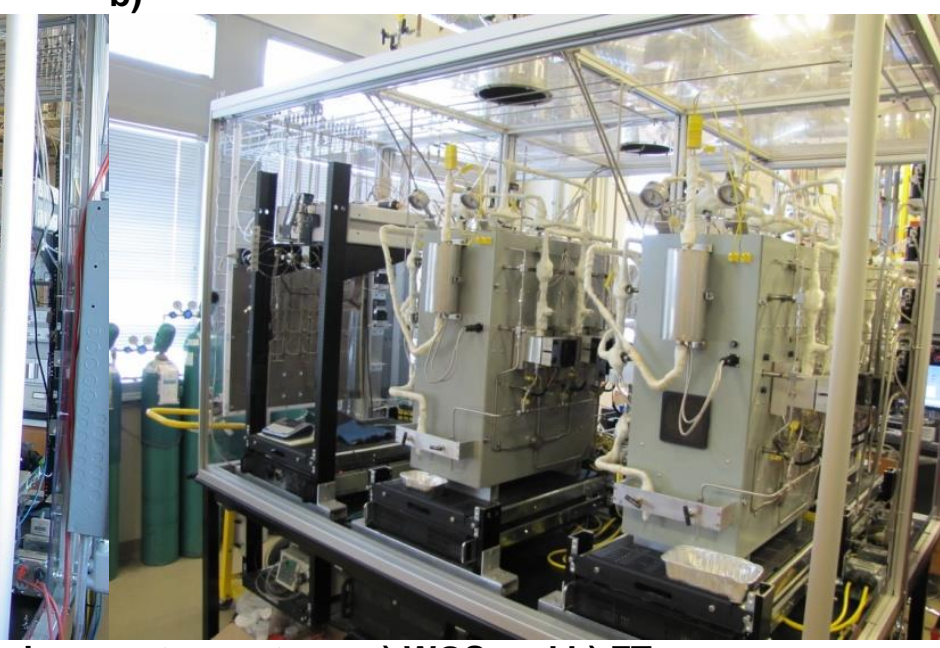

Figure 3-2. Laboratory-scale microreactor systems a) WGS and b) FT. 
regulated delivery of the reaction gases from compressed gas cylinders to the system. Argon (Ar) was included in the gas stream fed to the reactor as an internal standard used in product analysis. The WGS and FT catalysts were pretreated per manufacturer specifications before testing. After pretreatment, carbon monoxide $(\mathrm{CO}), \mathrm{CO}_{2}$, methane $\left(\mathrm{CH}_{4}\right)$, and hydrogen $\left(\mathrm{H}_{2}\right)$ were slowly added to reach the baseline syngas composition.

Because of the reactivity of $\mathrm{NH}_{3}$, special precautions were implemented to ensure that the $\mathrm{NH}_{3}$ concentration in the syngas seen by the catalysts was equivalent to the $\mathrm{NH}_{3}$ concentration in the syngas feed. In the presence of $\mathrm{NH}_{3}, \mathrm{CO}_{2}$, and $\mathrm{H}_{2} \mathrm{O}$ and at low temperatures, chemical reactions produce ammonium carbamate and/or ammonium bicarbonate. To inhibit conversion of $\mathrm{NH}_{3}$ in the syngas to carbamate and/or bicarbonate products, the syngas feed lines were heat-traced to maintain a temperature of $180{ }^{\circ} \mathrm{C}$, which is significantly higher than the decomposition temperature of these compounds. To mitigate reduction of $\mathrm{NH}_{3}$ concentration resulting from adsorption on the stainless steel tubing in the contaminant injection lines and equipment, all these tubing runs were passivated by exposure to $\mathrm{NH}_{3}$ for at least 48 hours prior to $\mathrm{NH}_{3}$ testing.

Reactant and product gases, including $\mathrm{C}_{1}-\mathrm{C}_{7}$ hydrocarbons, were analyzed by a Micro GC refinery gas analyzer (Agilent 3000). Condensed liquid samples, which included waxes, light hydrocarbons, and water, were collected every 48 to 72 hours in two sets of temperature-controlled traps. Waxes were collected in a trap held at $120^{\circ} \mathrm{C}$. Light hydrocarbons and water were collected in a trap maintained at 10 to $15^{\circ} \mathrm{C}$. For the WGS trials, only a cold trap $\left(10\right.$ to $\left.15^{\circ} \mathrm{C}\right)$ was necessary to collect any condensed water. For wax analysis, samples were manually injected into an Agilent 6890 GC equipped with a cool-oncolumn inlet, SPB-1 column, and flame ionization detector. Wax samples were prepared for GC analysis by dissolving in a small aliquot of $1 \mathrm{ml}$ carbon disulfide. FT wax $\alpha$ values for each sample were calculated using the Anderson-Schulz-Flory probability distribution equation:

$$
\log \left(\frac{C_{f r a c, i}}{N_{i}}\right)=(\log \alpha) N_{i}+K
$$

where $\mathrm{C}_{\text {frac, } \mathrm{i}}$ is the weight fraction of product with carbon number $\mathrm{N}_{\mathrm{i}}, \alpha$ is a parameter indicating the probability of chain growth, and $\mathrm{K}$ is a constant. Calibrations of analytical equipment were performed using calibration mixtures from Scott Specialty Gases.

\subsection{Experimental Conditions}

The specific temperature, pressure and baseline syngas compositions were selected that are representative of commercial operations for each catalyst and are presented in Table 3-2. To establish the typical performance of each catalyst, a baseline test was conducted in which the catalyst was exposed to the baseline syngas composition without any contaminants. This baseline test was continued until the catalyst performance had stabilized. The results from this baseline testing were used to set the initial baseline period during contaminant testing.

After loading the catalyst, a typical contaminant test consisted of a baseline period (without contaminants), which could range from 100 hours to 500 hours in duration followed by a maximum 1,000-h period with contaminants. For the multi-contaminant tests with $\mathrm{KCl}$ and/or $\mathrm{NaCl}$, the initial baseline period included the alkali contaminants because these contaminants were generated by vaporization of alkali salts upstream of the catalyst bed and loaded during the loading of the catalyst. During contaminant testing, the product composition was used to evaluate contaminant effect on catalyst performance. The conversion of CO resulting from the WGS reaction (Eq. 2) was used to monitor WGS catalyst performance. 


$$
\mathrm{H}_{2}+\mathrm{CO}=\mathrm{H}_{2} \mathrm{O}+\mathrm{CO}_{2}
$$

A potential competing reaction to the WGS reaction is the methanation reaction, $3 \mathrm{H}_{2}+\mathrm{CO}=\mathrm{H}_{2} \mathrm{O}+\mathrm{CH}_{4}$. Thus, selectivity for methane was also used to monitor the performance of WGS catalysts.

For FT synthesis, the primary reactions are FT reaction (Eq. 3) and WGS reaction (Eq. 2). Therefore for the FT catalysts, the $\mathrm{CO}$ conversion, rate of hydrocarbon and wax production, and distribution of hydrocarbons produced from the FT catalysts were used to monitor and evaluate catalyst performance.

$$
(2 n+1) \mathrm{H}_{2}+n \mathrm{CO}=\mathrm{n} \mathrm{H}_{2} \mathrm{O}+\mathrm{C}_{\mathrm{n}} \mathrm{H}_{(2 \mathrm{n}+2)}
$$

\begin{tabular}{|c|c|c|c|c|c|}
\hline \multirow[b]{2}{*}{ Component [vol\%] } & \multicolumn{5}{|c|}{ Catalyst system } \\
\hline & LTS & HTS & SGS & Fe-FT & Co-FT \\
\hline $\mathrm{H}_{2}$ & 36.1 & 17.7 & 21.3 & 41.3 & 42.7 \\
\hline $\mathrm{CO}$ & 4.6 & 23.0 & 27.7 & 24.3 & 21.3 \\
\hline $\mathrm{CO}_{2}$ & 29 & 10.6 & 12.8 & 29.9 & 31.6 \\
\hline $\mathrm{CH}_{4}$ & 2.8 & 2.8 & 3.4 & 4.5 & 4.4 \\
\hline $\mathrm{H}_{2} \mathrm{O}$ & 27.5 & 45.9 & 34.9 & 0 & 0 \\
\hline $\mathrm{H}_{2} \mathrm{~S}$ & 0 & 0 & $100 \mathrm{ppmv}$ & 0 & 0 \\
\hline Temperature $\left[{ }^{\circ} \mathbf{C}\right]$ & 200 & 375 & 250 & 250 & 210 \\
\hline Pressure [psig] & 500 & 500 & 500 & 350 & 350 \\
\hline Space velocity at $\mathrm{STP}\left[\mathrm{h}^{-1}\right]$ & 10,000 & 10,000 & 10,000 & 3,000 & 3,000 \\
\hline
\end{tabular}

Table 3-2. Baseline WGS and FT System Test Parameters 


\section{Experimental Results}

\subsection{Test Plan}

The test plan established with NETL included only multi-contaminant testing for the WGS catalysts but included a significant amount of individual contaminant testing for the FT catalysts. Table 4-1 summarizes the specific testing that was completed with each catalyst in this project. Because a large amount of information exists on individual contaminants for the different water gas shift catalyst, testing of these catalysts focused on potential synergistic effects from combinations of these contaminants.

Table 4-1. Project Test Matrix

\begin{tabular}{|l|c|c|c|c|c|c|c|}
\hline \multicolumn{1}{|c|}{ Catalyst } & Baseline & $\mathbf{H}_{2} \mathbf{S}$ & $\mathbf{C O S}$ & $\mathbf{N H}_{\mathbf{3}}$ & $\mathbf{N a C l}$ & $\mathbf{K C l}$ & $\mathbf{M C}^{\mathbf{1}}$ \\
\hline LTS & & Not tested & Not tested & Not tested & Not tested & Not tested & \\
\hline HTS & & Not tested & Not tested & Not tested & Not tested & Not tested & \\
\hline SGS & & Not tested & Not tested & Not tested & Not tested & Not tested & \\
\hline Fe-FT & & & & & & & \\
\hline Co-FT & & & & & & Not tested & \\
\hline
\end{tabular}

${ }^{1} \mathrm{MC}$ (Multi-contaminant): Tests completed with $\mathrm{NaCl}$ and $\mathrm{KCl}$ vapors, $\mathrm{H}_{2} \mathrm{~S}$, and $\mathrm{NH}_{3}$.

\subsection{LTS Catalyst Results}

\subsubsection{Baseline Testing}

As shown in Figure 4-1, 500 hours of testing were completed for the baseline trial on the LTS catalyst. The test conditions used for this trial were provided in Table 3-2. The predicted equilibrium conversion for the WGS reaction at these test conditions is $94.7 \%$. The actual CO conversion for this LTS catalyst in simulated clean $\mathrm{CB}$-derived syngas stabilized at $86.6 \%$ with no $\mathrm{CH}_{4}$ selectivity. 


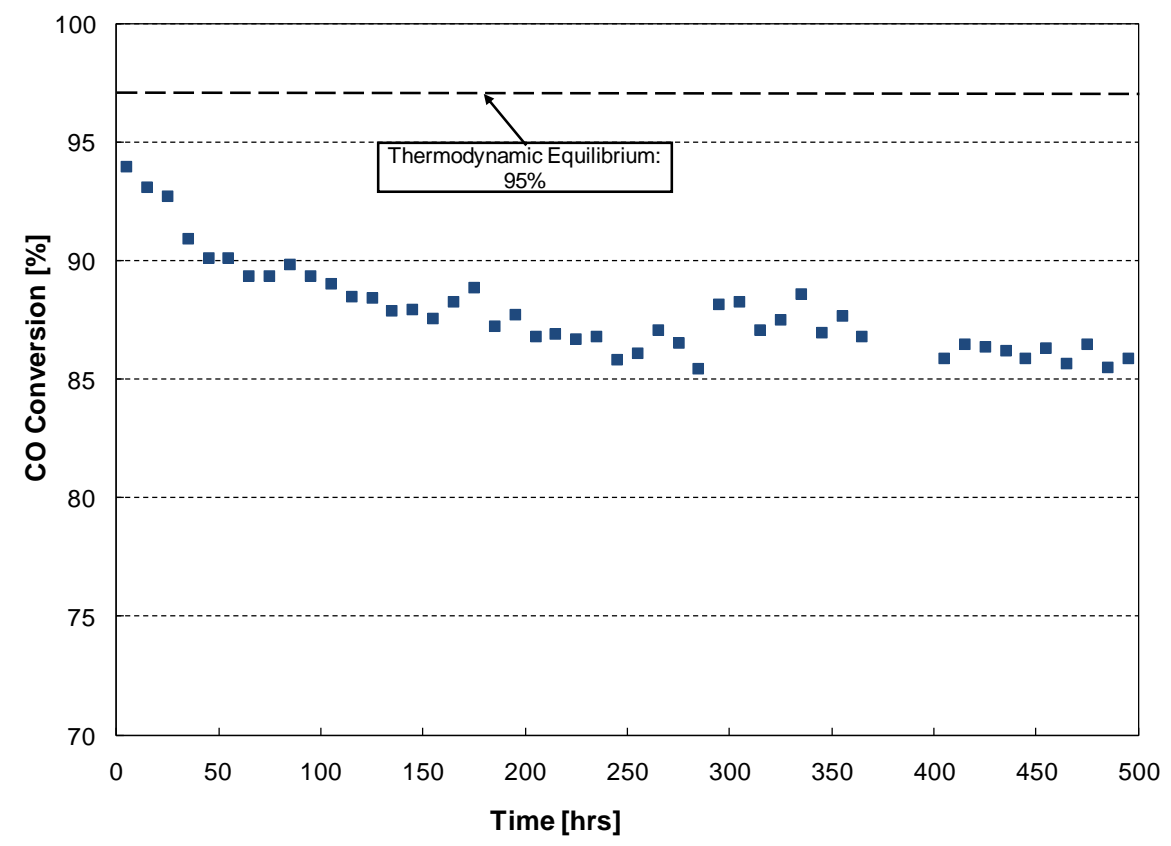

Figure 4-1. Baseline test results for the LTS catalyst.

\subsubsection{Multi-contaminant Exposure}

The primary objective of the multi-contaminant trial was to evaluate catalyst performance with a more realistic syngas mixture containing contaminants at precisely controlled concentrations to identify specific synergistic effects. The catalyst was sequentially exposed to different groups of contaminants so that changes in catalyst performance could be correlated with a specific group of contaminants. For this test, the LTS catalyst was exposed to a simulated $\mathrm{CB}$-derived syngas containing $\mathrm{NaCl}, \mathrm{KCl}, \mathrm{H}_{2} \mathrm{~S}$, and $\mathrm{NH}_{3}$. The alkali vapors were generated by vaporization of an alkali salt bed immediately upstream of the catalyst bed. Therefore, $\mathrm{NaCl}$ and $\mathrm{KCl}$ vapors were constantly present throughout this exposure trial. The specific concentrations of $\mathrm{NaCl}$ and $\mathrm{KCl}$ vapors present in the syngas were estimated based on the alkali vapor pressures at the specific testing conditions. This approach for estimating the alkali vapor concentrations was demonstrated during initial testing of alkali vapor generation. The estimated alkali concentrations for the test conditions given in Table 3-2 are provided in Table 4-2. The $\mathrm{H}_{2} \mathrm{~S}$ and $\mathrm{NH}_{3}$ were added as gas-phase contaminants to the simulated $\mathrm{CB}$-derived syngas. Targeted concentrations were 250, 500, and 1,000 parts per billion by volume (ppbv) for $\mathrm{NH}_{3}$ and 1,000 ppbv for $\mathrm{H}_{2} \mathrm{~S}$.

Table 4-2. Concentrations of Alkali Vapors during Testing with Simulated CB-Derived Syngas

\begin{tabular}{|l|c|c|}
\hline \multirow{2}{*}{ Catalyst } & \multicolumn{2}{|c|}{ Alkali vapor concentration (pptv) } \\
\cline { 2 - 3 } & NaCl & KCI \\
\hline LTS & $2.5 \times 10^{-4}$ & $2 \times 10^{-7}$ \\
\hline HTS & 30.6 & 1.6 \\
\hline SGS & $1.6 \times 10^{-2}$ & $5.6 \times 10^{-5}$ \\
\hline Fe-FT & $2.2 \times 10^{-2}$ & $7.9 \times 10^{-5}$ \\
\hline Co-FT & $8.6 \times 10^{-4}$ & $9.7 \times 10^{-7}$ \\
\hline
\end{tabular}


CO conversion in the multi-contaminant trial on the LTS catalyst is shown in Figure 4-2. Additional analysis of LTS catalyst performance is provided in Table 4-3. Compared with the baseline trial, the LTS catalyst performance stabilized at a slightly lower CO conversion in the presence of alkali vapors (80\% vs. 87\%). However, this lower performance cannot be solely attributed to alkali vapors because it may be a result of variability in catalyst samples and/or catalyst activation. Little effect was seen between combinations of alkali vapors with $\mathrm{NH}_{3}$ and $\mathrm{H}_{2} \mathrm{~S}$. The multi-contaminant trial results also indicate that no decline in $\mathrm{CO}$ conversion is observed in $\mathrm{NH}_{3}$ and $\mathrm{H}_{2} \mathrm{~S}$ concentrations as high as 1,000 ppbv after 1,100 hours of operation.

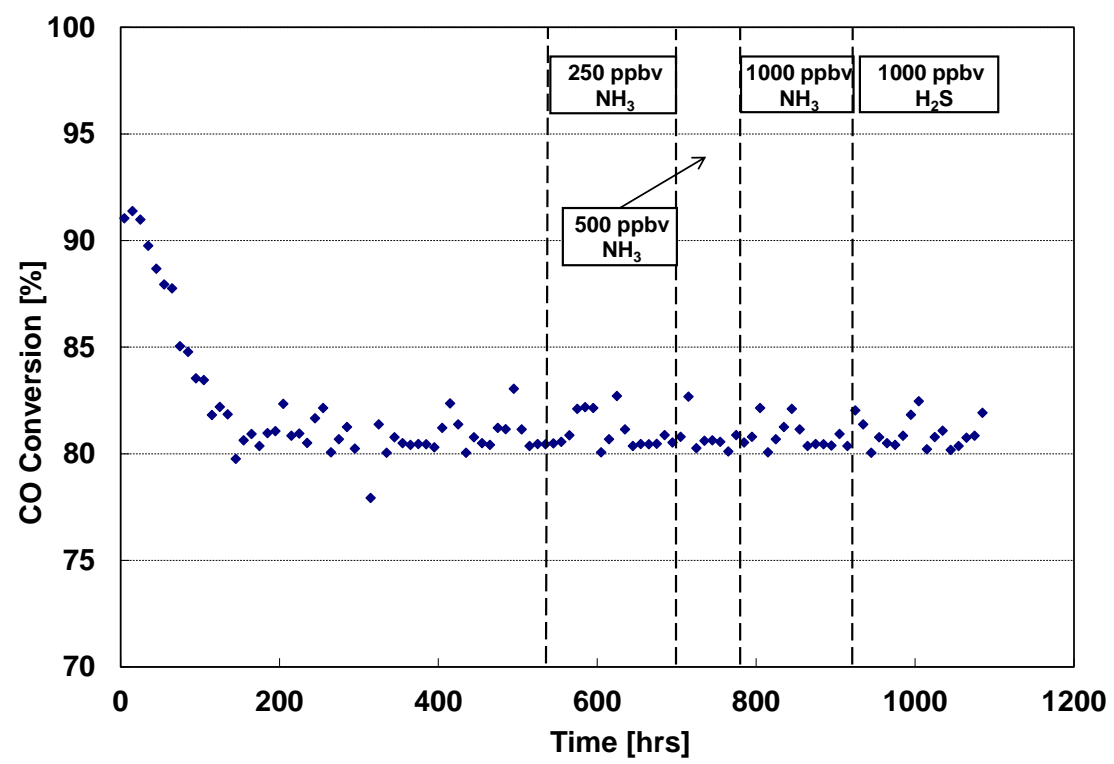

Figure 4-2. Multi-contaminant exposure results for the LTS catalyst.

Table 4-3. LTS Catalyst Performance during Multi-contaminant Testing

\begin{tabular}{|c|c|c|c|c|c|}
\hline \multirow[b]{2}{*}{$\begin{array}{l}\text { Performance } \\
\text { parameter }\end{array}$} & \multicolumn{5}{|c|}{ Contaminants } \\
\hline & Alkali $^{1}$ & $\begin{array}{c}\text { Alkali }^{1}+ \\
250 \text { ppbv }^{2} \\
\mathrm{NH}_{3}\end{array}$ & $\begin{array}{c}\text { Alkali }^{1}+ \\
500 \text { ppbv }^{2} \\
\mathrm{NH}_{3}\end{array}$ & $\begin{array}{c}\text { Alkali }^{1}+ \\
1,000 \text { ppbv } \\
\mathrm{NH}_{3}\end{array}$ & $\begin{array}{c}\text { Alkali }^{1}+ \\
1,000 \text { ppbv } \\
\mathrm{H}_{2} \mathrm{~S}\end{array}$ \\
\hline Exposure time [h] & 570 & 130 & 90 & 110 & 130 \\
\hline CO conversion [\%] & 80.4 & 80.4 & 80.6 & 80.4 & 80.2 \\
\hline $\mathrm{CH}_{4}$ selectivity [\%] & $\mathrm{ND}^{2}$ & $\mathrm{ND}^{2}$ & $\mathrm{ND}^{2}$ & $\mathrm{ND}^{2}$ & $\mathrm{ND}^{2}$ \\
\hline
\end{tabular}

${ }^{1}$ Alkali $=\mathrm{NaCl}$ and $\mathrm{KCl}$ vapors (with concentrations given in Table 4-2)

${ }^{2} \mathrm{ND}=$ No selectivity for $\mathrm{CH}_{4}$ was detected.

\subsection{HTS Catalyst Results}

\subsubsection{Baseline Testing}

For the baseline trial on the HTS catalyst, the microreactor system was operated for a total of 500 hours. The experimental results are shown in Figure 4-3. The predicted equilibrium conversion for the WGS reaction on the HTS catalyst at the test conditions given in Table $3-2$ is $87.5 \%$. The actual CO conversion determined for this HTS catalyst in simulated clean CB-derived syngas stabilized at $78.3 \%$. 


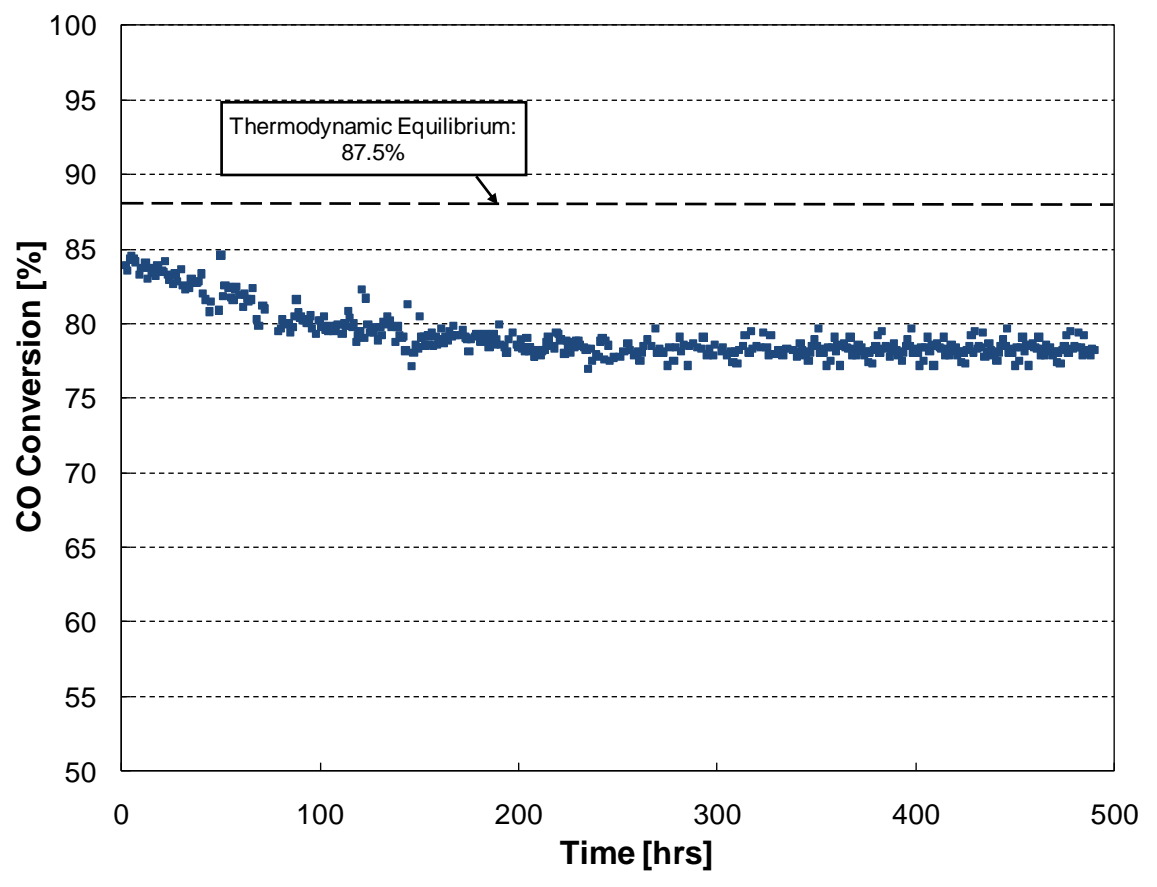

Figure 4-3. Baseline test results for the HTS catalyst.

\subsubsection{Multi-contaminant Exposure}

Figure 4-4 illustrates how the HTS catalyst performance, as measured by CO conversion, changed during the multi-contaminant exposure trial (blue data symbols) and compares it with the baseline test data (red data symbols). Table 4-4 shows the averaged $\mathrm{CO}$ conversion and $\mathrm{CH}_{4}$ selectivity values for different groups of contaminant exposure. The most visible effect during this multi-contaminant testing was the significant decrease in $\mathrm{CO}$ conversion observed during exposure to $\mathrm{NaCl}, \mathrm{KCl}$, and 1 parts per million by volume (ppmv) $\mathrm{H}_{2} \mathrm{~S}$. Interestingly, upon removal of $1 \mathrm{ppmv}_{2} \mathrm{~S}, \mathrm{CO}$ conversion increased and returned to approximately the same conversion before the addition of $\mathrm{H}_{2} \mathrm{~S}$. The difference in $\mathrm{CO}$ conversion during the baseline period from the multi-contaminant test and the baseline test suggest that exposure to alkali vapors could improve CO conversion. Although the commercial HTS catalyst used in this study does not contain an alkali promoter, alkali promoters are commonly used in many commercial Fe-based catalysts and could potentially explain the enhanced performance seen during exposure to the alkali vapors in this test.

When the HTS catalyst was exposed to simulated syngas containing $\mathrm{H}_{2} \mathrm{~S}, \mathrm{NH}_{3}$, or combinations of these two contaminants in addition to alkali vapors, the $\mathrm{CO}$ conversion was observed to steadily decline. To evaluate any subtle changes that were not identified by visual inspection, statistical analysis was used to compare changes in the rate of $\mathrm{CO}$ conversion for these different contaminant groups. Based on this analysis, the lowest statistically significant decline in $\mathrm{CO}$ conversion was observed with the combination of 1 ppmv $\mathrm{NH}_{3}, 150$ ppbv $\mathrm{H}_{2} \mathrm{~S}$, and alkali vapors, demonstrating the compounding effect of multiple contaminants. 


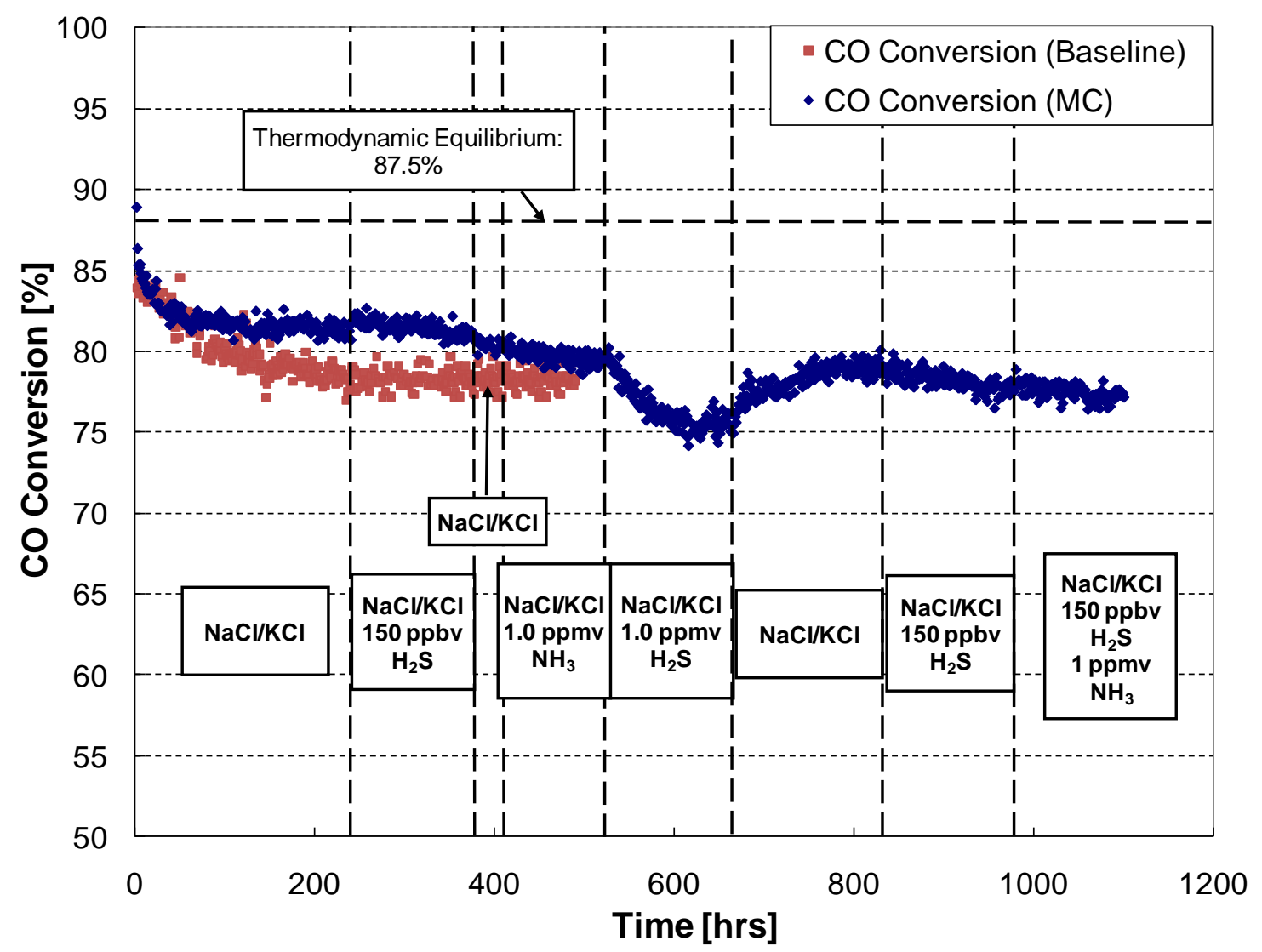

Figure 4-4. CO conversion of the HTS catalyst in the presence of syngas containing multiple contaminants.

Table 4-4. HTS Catalyst Performance during Multi-contaminant Testing

\begin{tabular}{|c|c|c|c|c|c|c|c|c|}
\hline \multirow[b]{2}{*}{$\begin{array}{c}\text { Performance } \\
\text { parameter }\end{array}$} & \multicolumn{8}{|c|}{ Contaminants } \\
\hline & Alkali $^{1}$ & $\begin{array}{c}\text { Alkali }^{1}+ \\
150 \text { ppbv }^{+} \\
\mathrm{H}_{2} \mathrm{~S}\end{array}$ & Alkali $^{1}$ & $\begin{array}{c}\text { Alkali }^{1}+ \\
1,000 \text { ppbv } \\
\mathrm{NH}_{3}\end{array}$ & $\begin{array}{c}\text { Alkali }^{1}+ \\
1,000 \text { ppbv } \\
\mathrm{H}_{2} \mathrm{~S}\end{array}$ & Alkali $^{1}$ & $\begin{array}{c}\text { Alkali }^{1}+ \\
150 \text { ppbv } \\
\mathrm{H}_{2} \mathrm{~S}\end{array}$ & $\begin{array}{c}\text { Alkali }^{1}+ \\
1,000 \text { ppbv } \\
\mathrm{NH}_{3}+150 \\
\text { ppbv } \mathrm{H}_{2} \mathrm{~S}\end{array}$ \\
\hline Exposure time [h] & 90 & 125 & 30 & 110 & 150 & 165 & 100 & 160 \\
\hline CO conversion [\%] & 81 & 81 & 80 & 79 & 76 & 79 & 78 & 77 \\
\hline $\mathrm{CH}_{4}$ selectivity [\%] & $\mathrm{ND}^{2}$ & $\mathrm{ND}^{2}$ & $\mathrm{ND}^{2}$ & $\mathrm{ND}^{2}$ & $\mathrm{ND}^{2}$ & $\mathrm{ND}^{2}$ & $\mathrm{ND}^{2}$ & $\mathrm{ND}^{2}$ \\
\hline
\end{tabular}

${ }^{1}$ Alkali $=\mathrm{NaCl}$ and $\mathrm{KCl}$ vapors (with concentrations given in Table 4-2)

${ }^{2} \mathrm{ND}=$ No selectivity for $\mathrm{CH}_{4}$ was detected. 


\subsection{SGS Catalyst Results}

\subsubsection{Baseline Testing}

A total of 500 hours of operation was completed for the baseline test on the SGS catalyst. The predicted equilibrium conversion for the WGS reaction on the SGS catalyst under the test conditions given in Table 3-2 is $92.2 \%$. As shown in Figure 4-5, the actual CO conversion for this SGS catalyst in the microreactor system using simulated clean CB-derived syngas stabilized at $78.3 \%$.

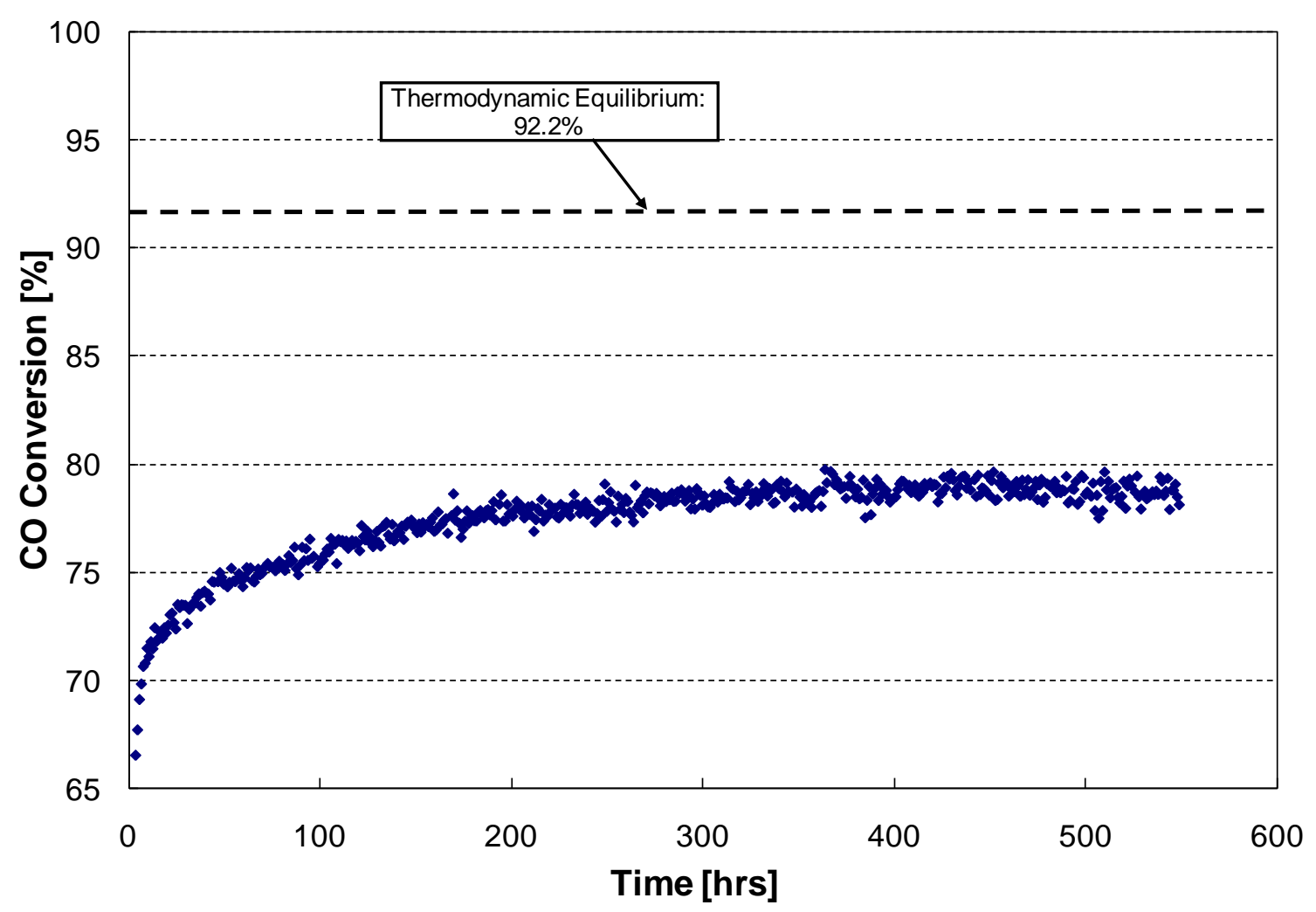

Figure 4-5. Baseline test results for the SGS catalyst.

\subsubsection{Multi-contaminant Exposure}

For the SGS catalyst multi-contaminant trial, the catalyst was exposed to a simulated CB-derived syngas containing $\mathrm{NaCl}, \mathrm{KCl}$, and $\mathrm{NH}_{3}$ (concentrations for alkali species provided in Table 4-2). Although $\mathrm{H}_{2} \mathrm{~S}$ is present in the baseline syngas mixture for this catalyst, the $\mathrm{H}_{2} \mathrm{~S}$ is not considered a contaminant as the $\mathrm{H}_{2} \mathrm{~S}$ concentration in the baseline syngas mixture is necessary for maintaining the active sulfide species for the WGS reaction and is the reason SGS catalyst are suitable for syngas applications with high $\mathrm{H}_{2} \mathrm{~S}$ concentrations. The $\mathrm{CO}$ conversion for this test is compared with that measured in the baseline test in Figure 4-6, and averaged values for $\mathrm{CO}$ conversion and $\mathrm{CH}_{4}$ selectivity for the different contaminant groups are provided in Table 4-5. Because no significant visible differences were observed, statistical analysis, which consisted of a t-test with null hypothesis that the rate of change are identical, was used to assess changes in the rate of $\mathrm{CO}$ conversion during exposure to the different contaminants. This analysis found no statistical difference in $\mathrm{CO}$ conversion rates for simulated $\mathrm{CB}$-derived syngas mixtures with alkali only and with alkali plus 1 ppmv $\mathrm{NH}_{3}$ compared with simulated clean $\mathrm{CB}$-derived syngas. 


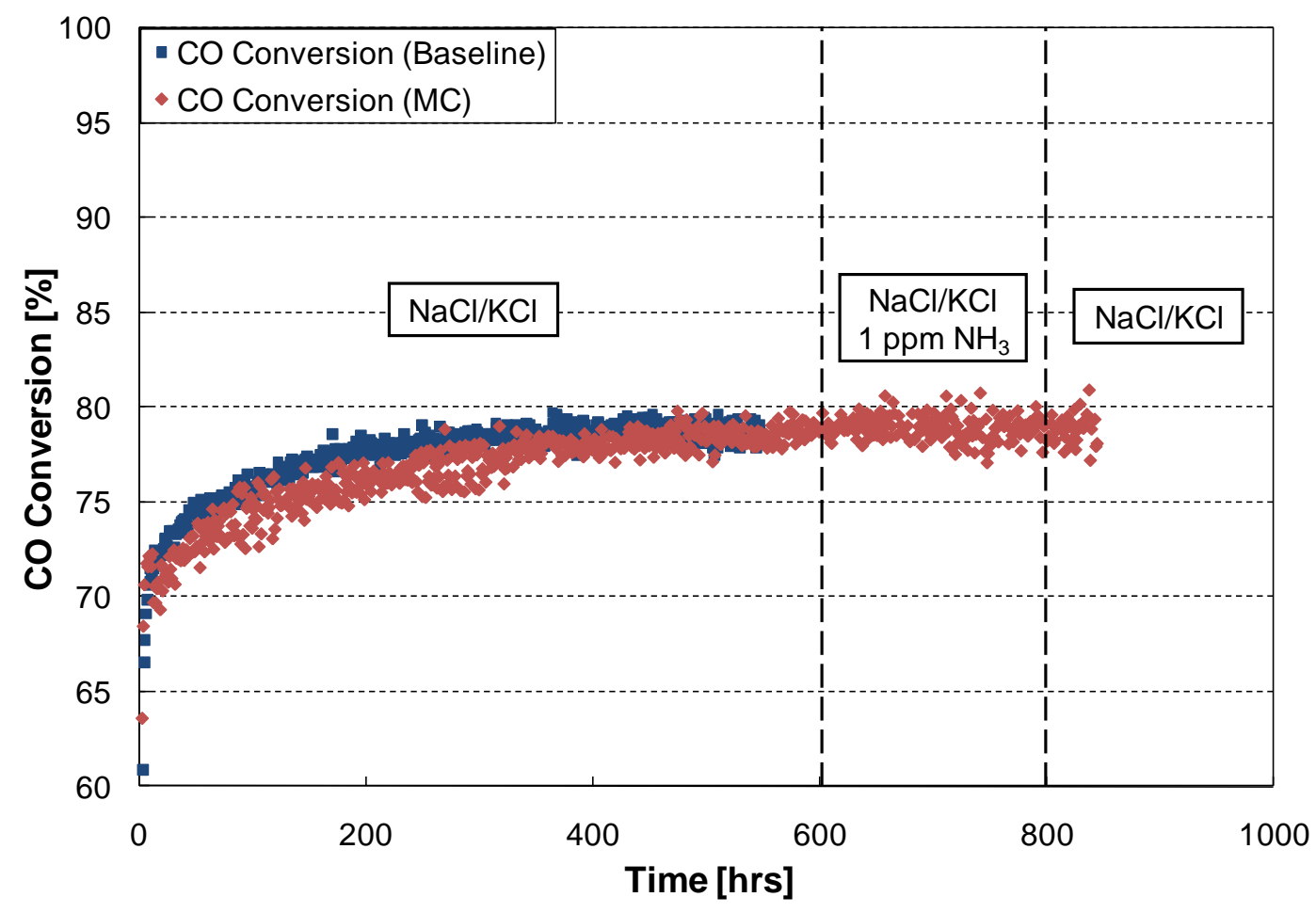

Figure 4-6. CO conversion of the SGS catalyst in multi-contaminant exposure testing.

Table 4-5. SGS Catalyst Performance during Multi-contaminant Testing

\begin{tabular}{|l|c|c|c|}
\hline \multirow{2}{*}{ Performance parameter } & \multicolumn{3}{|c|}{ Contaminants } \\
\cline { 2 - 4 } & Alkali $^{\mathbf{1}}$ & Alkali $^{\mathbf{1}} \mathbf{1}$ ppmv $\mathbf{~ H H}_{\mathbf{3}}$ & Alkali $^{\mathbf{1}}$ \\
\hline Exposure time [h] & 600 & 700 & 840 \\
\hline CO conversion [\%] & 78.8 & 78.9 & 78.8 \\
\hline $\mathbf{C H}_{\mathbf{4}}$ selectivity [\%] & $\mathrm{ND}^{2}$ & $\mathrm{ND}^{2}$ & $\mathrm{ND}^{2}$ \\
\hline
\end{tabular}

${ }^{1}$ Alkali $=\mathrm{NaCl}$ and $\mathrm{KCl}$ vapors (with concentrations given in Table 4-2)

${ }^{2} \mathrm{ND}=$ No selectivity for $\mathrm{CH}_{4}$ was detected.

\subsection{Fe-FT Catalyst Test Results}

\subsubsection{Baseline Testing}

Figure 4-7 presents $\mathrm{CO}$ conversion for the Fe-FT catalyst in the baseline syngas. Although some changes in the Fe-FT catalyst performance were seen during the first 150 minutes of baseline syngas exposure (i.e., there was a period of increased $\mathrm{CO}$ conversion followed by decline or break-in period as seen in other testing), its performance during the next 350 minutes was very consistent and stable. Table 4-6 provides the ranges of $\mathrm{CH}_{4}$ and $\mathrm{CO}_{2}$ selectivities, catalyst productivity, and FT wax $\alpha$ (Eq. 1) during this 350-min period of stable operation. Based on these results, subsequent Fe-FT catalyst testing was conducted in clean syngas for at least 150 hours to stabilize the catalyst activity before contaminant exposure was initiated. 


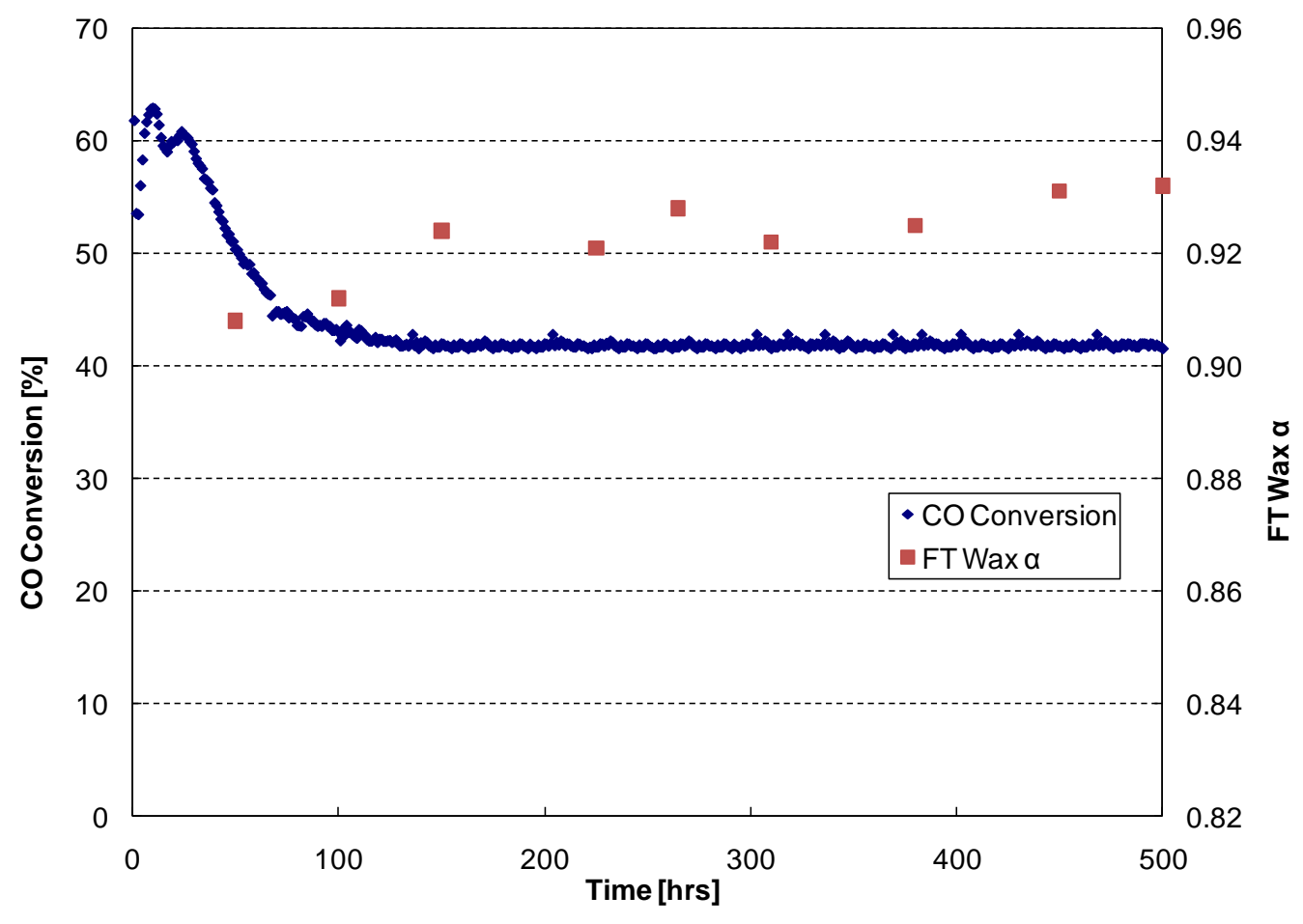

Figure 4-7. Baseline test results for the Fe-FT catalyst.

Table 4-6. Baseline Fe-FT Catalyst Performance and Selectivities

\begin{tabular}{|c|c|}
\hline Performance parameter & Value for Fe-FT catalyst \\
\hline Average CO conversion [\%] & $41-42$ \\
\hline $\begin{array}{l}\text { Catalyst productivity } \\
\text { [mg C }{ }_{5+} / \mathrm{h} / \text { g catalyst] }\end{array}$ & $168-172$ \\
\hline $\mathrm{CH}_{4}$ selectivity [\%] & $1-2$ \\
\hline $\mathrm{CO}_{2}$ selectivity [\%] & $30-36$ \\
\hline FT wax $\alpha$ & $0.90-0.93$ \\
\hline
\end{tabular}




\subsubsection{Exposure to $\mathrm{H}_{2} \mathrm{~S}$}

To establish its tolerance to $\mathrm{H}_{2} \mathrm{~S}$, the Fe-FT catalyst was exposed to $\mathrm{H}_{2} \mathrm{~S}$ over the concentration range of 100 to $200 \mathrm{ppbv}$. The unexplained initial increase in $\mathrm{CO}$ conversion within the first several hours of testing was again observed, followed by decline and stabilization. The $\mathrm{CO}$ conversion and FT wax $\alpha$ profiles for these trials are shown in Figures 4-8 and 4-9, and Table 4-7 provides the average values of catalyst productivity, $\mathrm{CO}$ conversion, and $\mathrm{CH}_{4}$ and $\mathrm{CO}_{2}$ selectivities. Results after 200 hours of $100 \mathrm{ppbv}$ $\mathrm{H}_{2} \mathrm{~S}$ exposure showed no measurable impact on catalyst performance between clean syngas and syngas with $100 \mathrm{ppbv}$ of $\mathrm{H}_{2} \mathrm{~S}$. With syngas containing $150 \mathrm{ppbv} \mathrm{H}_{2} \mathrm{~S}$, the $\mathrm{CO}$ conversion and catalyst productivity of the Fe-FT slowly decreased. When the $\mathrm{H}_{2} \mathrm{~S}$ concentration was increased to $175 \mathrm{ppbv}$, the rates of decrease in $\mathrm{CO}$ conversion and catalyst productivity increased. Additional testing in a second trial with syngas containing $200 \mathrm{ppbv}_{2} \mathrm{~S}$ demonstrated further performance degradation. These results indicate that the $\mathrm{H}_{2} \mathrm{~S}$ tolerance of this commercial Fe-FT catalyst was about 100 ppbv.

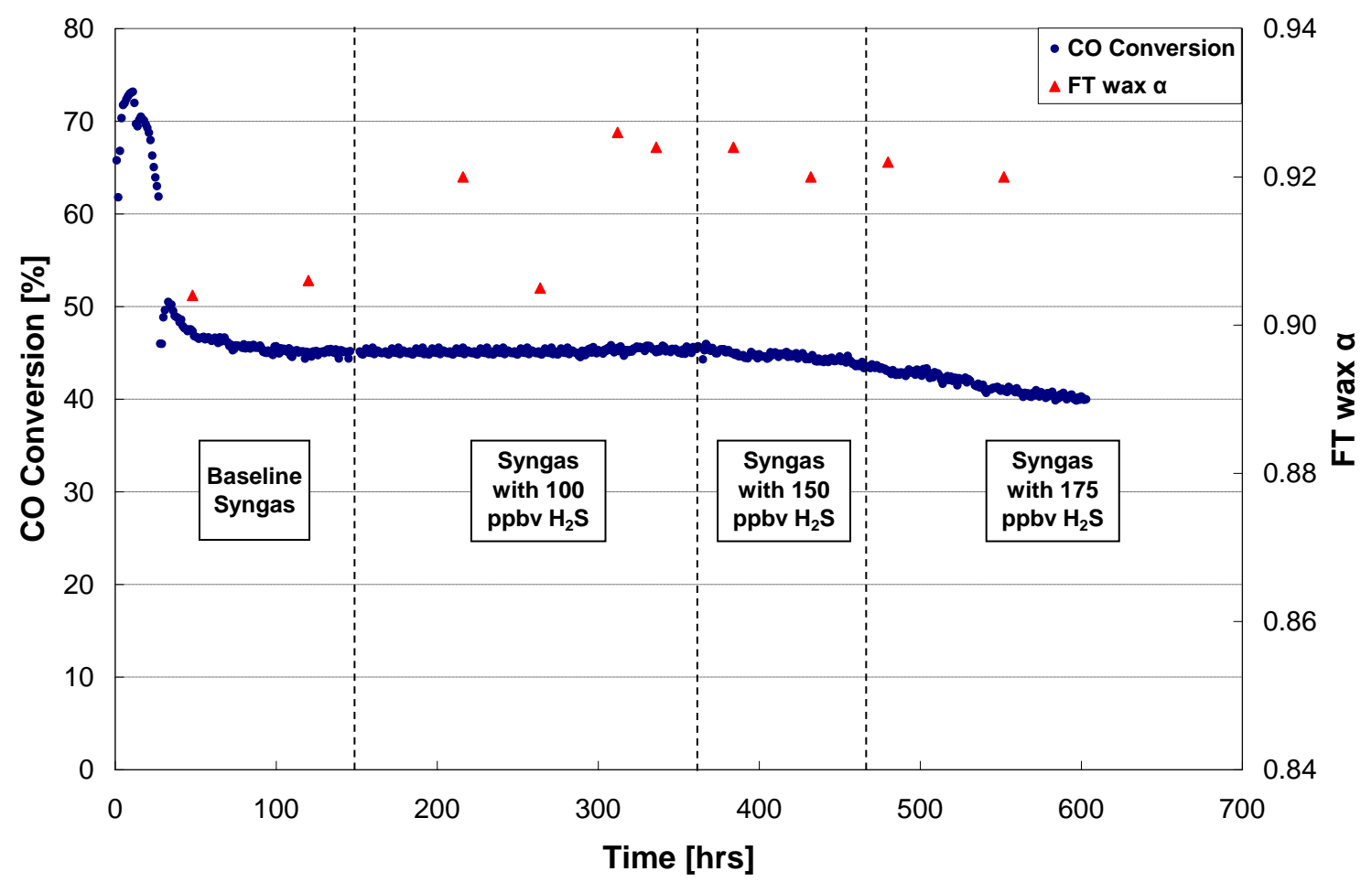

Figure 4-8. Fe-FT catalyst performance with 100, 150, and 175 ppbv $\mathrm{H}_{2} \mathrm{~S}$. 


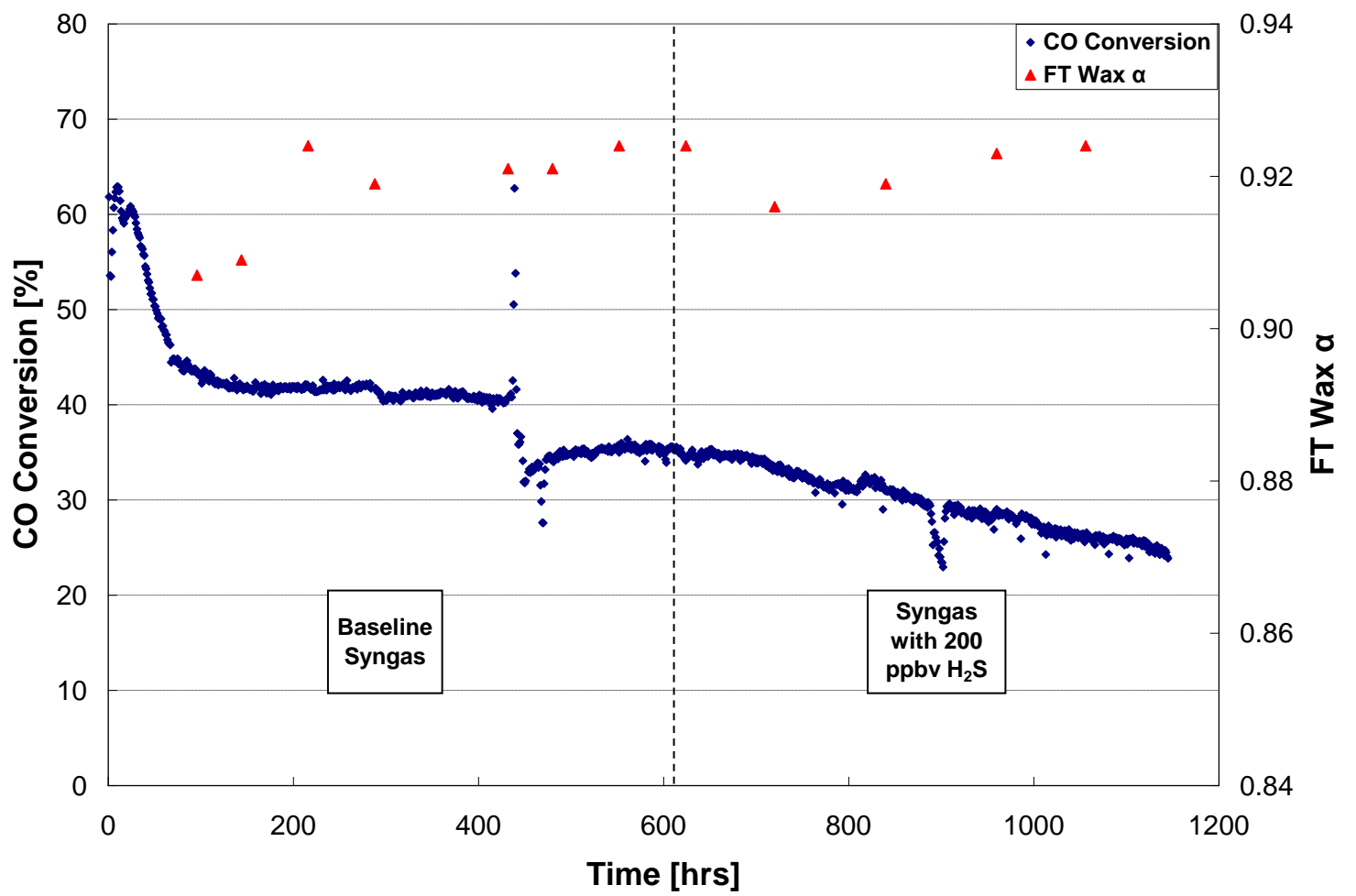

Figure 4-9. Fe-FT catalyst performance with 200 ppbv $\mathrm{H}_{2} \mathrm{~S}$.

Table 4-7. Effect of $\mathrm{H}_{2} \mathrm{~S}$ Concentration on Fe-FT Catalyst Performance

\begin{tabular}{|c|c|c|c|c|c|}
\hline \multirow{2}{*}{ Performance parameter } & \multicolumn{5}{|c|}{$\mathrm{H}_{2} \mathrm{~S}$ contaminant concentration (ppbv) } \\
\hline & $\mathbf{0}$ & 100 & 150 & 175 & 200 \\
\hline Exposure time [h] & 150 & 110 & 100 & 130 & 550 \\
\hline CO conversion [\%] & 45.6 & 45.6 & 44.5 & 42.5 & 24.9 \\
\hline $\begin{array}{l}\text { Catalyst productivity } \\
\text { [mg C } \mathrm{m}_{5} / \mathrm{h} / \mathrm{g} \text { catalyst] }\end{array}$ & 208 & 208 & 200 & 186 & 103 \\
\hline $\mathrm{CH}_{4}$ selectivity [\%] & 1.2 & 1.2 & 1.2 & $\mathbf{N A}^{1}$ & 1.2 \\
\hline $\mathrm{CO}_{2}$ selectivity [\%] & 29 & 29 & 29 & 29 & 29 \\
\hline FT wax $\alpha$ & $0.90-0.92$ & $0.90-0.92$ & $0.90-0.92$ & $0.90-0.92$ & $0.90-0.92$ \\
\hline
\end{tabular}

${ }^{1}$ NA Not available

\subsubsection{Exposure to COS}

To determine the effect of COS on the Fe-FT catalyst performance, tests were performed with syngas containing four different COS concentrations $(125,150,175$, and $200 \mathrm{ppbv})$. The CO conversion and FT wax $\alpha$ profiles for these tests are shown in Figures 4-10 and 4-11, and Table 4-8 provides the average values of catalyst productivity, $\mathrm{CO}$ conversion, and $\mathrm{CH}_{4}$ and $\mathrm{CO}_{2}$ selectivities. Up to concentrations of $150 \mathrm{ppbv}$, COS had little impact on the Fe-FT catalyst performance. However, a noticeable decrease in catalyst productivity and $\mathrm{CO}$ conversion was observed when this Fe-FT catalyst was exposed to syngas with 175 ppbv COS. During exposure to 200 ppbv COS, the degradation of CO conversion and catalyst productivity was even more pronounced. In the second test trial, the Fe-FT catalyst was re-evaluated with clean syngas after 300 hours of COS exposure to determine if the sulfur poisoning was permanent. After 
65 hours in clean syngas, no improvement in CO conversion or catalyst productivity was observed, thereby demonstrating that the decline in catalyst activity was irreversible.

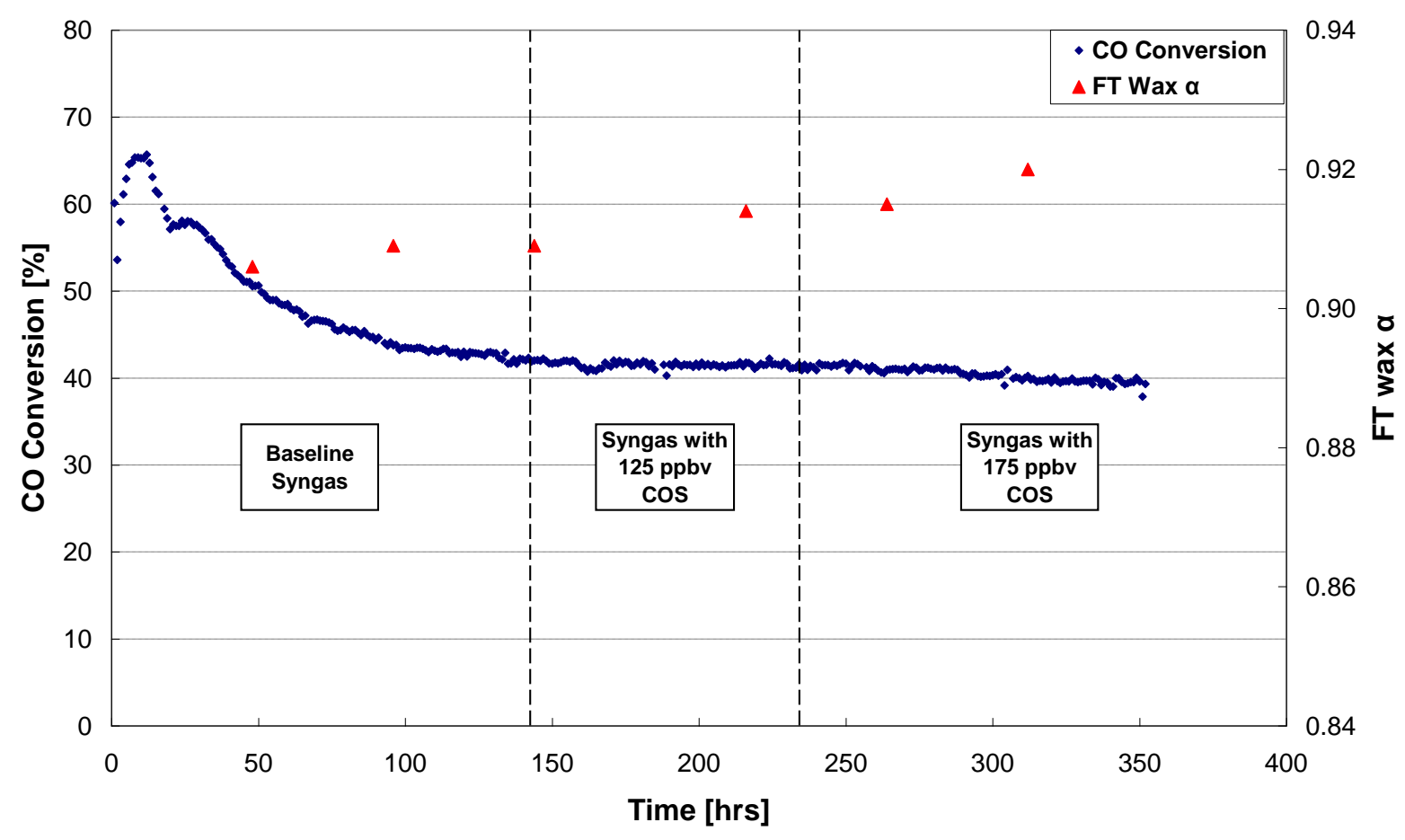

Figure 4-10. Fe-FT catalyst performance with 125 and 175 ppbv COS in syngas.

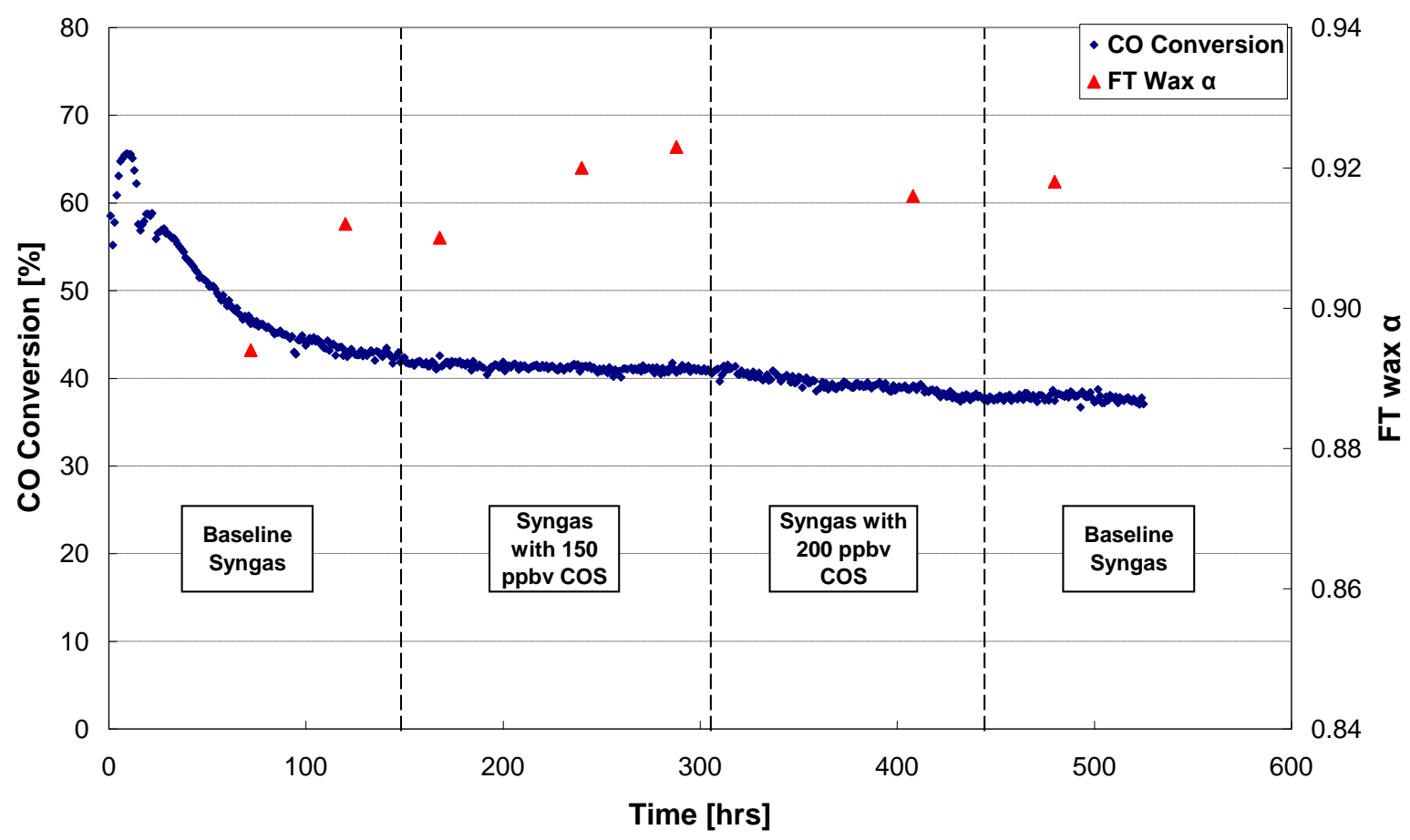

Figure 4-11. Fe-FT catalyst performance with 150 and 200 ppbv COS. 
Table 4-8. Effect of COS Concentration on Fe-FT Catalyst Performance

\begin{tabular}{|l|c|c|c|c|c|}
\hline \multirow{2}{*}{ Performance parameter } & \multicolumn{5}{|c|}{ COS contaminant concentration (ppbv) } \\
\cline { 2 - 6 } & $\mathbf{0}$ & $\mathbf{1 2 5}$ & $\mathbf{1 5 0}$ & $\mathbf{1 7 5}$ & $\mathbf{2 0 0}$ \\
\hline Exposure time [h] & 140 & 110 & 155 & 170 & 125 \\
\hline CO conversion [\%] & 42.3 & 42.3 & 39.4 & 39.4 & 36.5 \\
\hline $\begin{array}{l}\text { Catalyst productivity } \\
\text { [mg } \mathbf{C}_{\mathbf{5}} / \mathbf{h} / \mathbf{g} \text { catalyst] }\end{array}$ & 208 & 210 & 208 & 208 & 196 \\
\hline $\mathbf{C H}_{\mathbf{4}}$ selectivity [\%] & 1.9 & 1.9 & 1.9 & 1.9 & 1.9 \\
\hline $\mathbf{C O}_{\mathbf{2}}$ selectivity [\%] & 32 & 32 & 32 & 32 & 32 \\
\hline FT wax $\boldsymbol{\alpha}$ & $0.90-0.92$ & $0.90-0.92$ & $0.90-0.92$ & $0.90-0.92$ & $0.90-0.92$ \\
\hline
\end{tabular}

The sulfur contaminant test results on the Fe-FT catalyst clearly show that, at the same concentration, $\mathrm{H}_{2} \mathrm{~S}$ degraded the catalyst performance more rapidly than COS. At sulfur concentrations above $150 \mathrm{ppbv}$ for either $\mathrm{H}_{2} \mathrm{~S}$ or COS, the Fe-FT catalyst performance began to decrease. At sulfur concentrations below $100 \mathrm{ppbv}$ for either $\mathrm{H}_{2} \mathrm{~S}$ or COS, no or only minimal decrease in catalyst performance was observed.

\subsubsection{Exposure to $\mathrm{NH}_{3}$}

The effect of 0.1 to $1.0 \mathrm{ppmv}$ of $\mathrm{NH}_{3}$ in syngas on the Fe-FT catalyst performance was evaluated in a single trial. $\mathrm{NH}_{3}$ was introduced by metering a certified $\mathrm{H}_{2} / \mathrm{NH}_{3}$ mixture into the syngas feed with a mass flow controller. Specific precautions to avoid a reduction in $\mathrm{NH}_{3}$ concentration in the syngas due to undesired reactions and adsorption during catalyst exposure were discussed in Section 3.2. The CO conversion and FT wax $\alpha$ profiles for this test are shown in Figure 4-12. Average values for other catalyst performance parameters during the exposure to syngas with different $\mathrm{NH}_{3}$ concentrations are provided in Table 4-9. From the $\mathrm{NH}_{3}$ exposure trial results, $\mathrm{NH}_{3}$ concentrations below 1 ppmv do not have a measurable impact on the Fe-FT catalyst performance. 


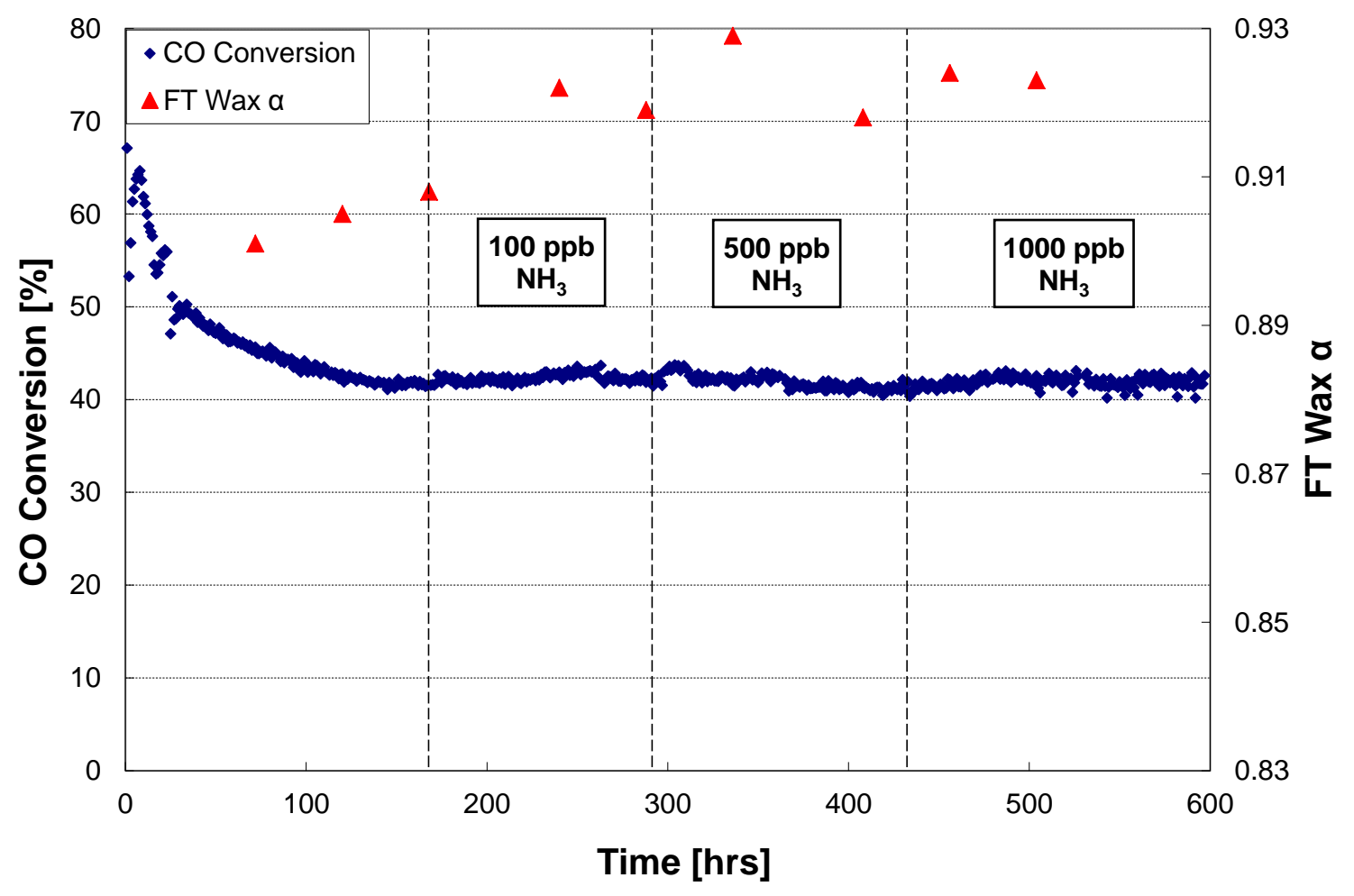

Figure 4-12. Fe-FT catalyst performance with 100, 500, and 1,000 ppbv $\mathrm{NH}_{3}$.

Table 4-9. Effect of $\mathrm{NH}_{3}$ Concentration on Fe-FT Catalyst Performance

\begin{tabular}{|l|c|c|c|c|}
\hline \multirow{2}{*}{ Performance parameter } & \multicolumn{4}{|c|}{$\mathbf{N H}_{\mathbf{3}}$ contaminant concentration (ppbv) } \\
\cline { 2 - 5 } & $\mathbf{0}$ & $\mathbf{1 0 0}$ & $\mathbf{5 0 0}$ & $\mathbf{1 , 0 0 0}$ \\
\hline Exposure time [h] & 175 & 125 & 150 & 150 \\
\hline CO conversion [\%] & 42 & 42 & 42 & 42 \\
\hline $\begin{array}{l}\text { Catalyst productivity } \\
\text { [mg C }\end{array}$ / $/ \mathbf{h}$ g catalyst] & 168 & 164 & 160 & 160 \\
\hline $\mathbf{C H}_{\mathbf{4}}$ selectivity [\%] & 2 & 2 & 2 & 2 \\
\hline $\mathbf{C O}_{\mathbf{2}}$ selectivity [\%] & 33 & 34 & 36 & 36 \\
\hline FT wax $\boldsymbol{\alpha}$ & $0.91-0.93$ & $0.91-0.93$ & $0.91-0.93$ & $0.91-0.93$ \\
\hline
\end{tabular}

\subsubsection{Exposure to NaCl Vapor}

The effect of syngas containing $\mathrm{NaCl}$ vapor on the Fe-FT catalyst performance was evaluated for 400 hours. Figure 4-13 shows CO conversion and FT wax $\alpha$ profiles for this trial, and Table 4-10 provides the average values for $\mathrm{CO}$ conversion, catalyst productivity, and $\mathrm{CH}_{4}$ and $\mathrm{CO}_{2}$ selectivities for the baseline syngas case and syngas with $\mathrm{NaCl}$ vapor. Comparison of the Fe-FT catalyst performance in the presence of $\mathrm{NaCl}$ vapor with baseline syngas conditions shows that the overall catalyst performance was similar in both these reaction environments. The stabilized $\mathrm{CO}$ conversion and catalyst productivity with $\mathrm{NaCl}$ vapor was slightly higher, but this could be attributed to variability in catalyst samples tested 
and/or catalyst activation. In general, it can be concluded from these contaminant test results that $\mathrm{NaCl}$ vapor does not adversely affect the Fe-FT catalyst performance.

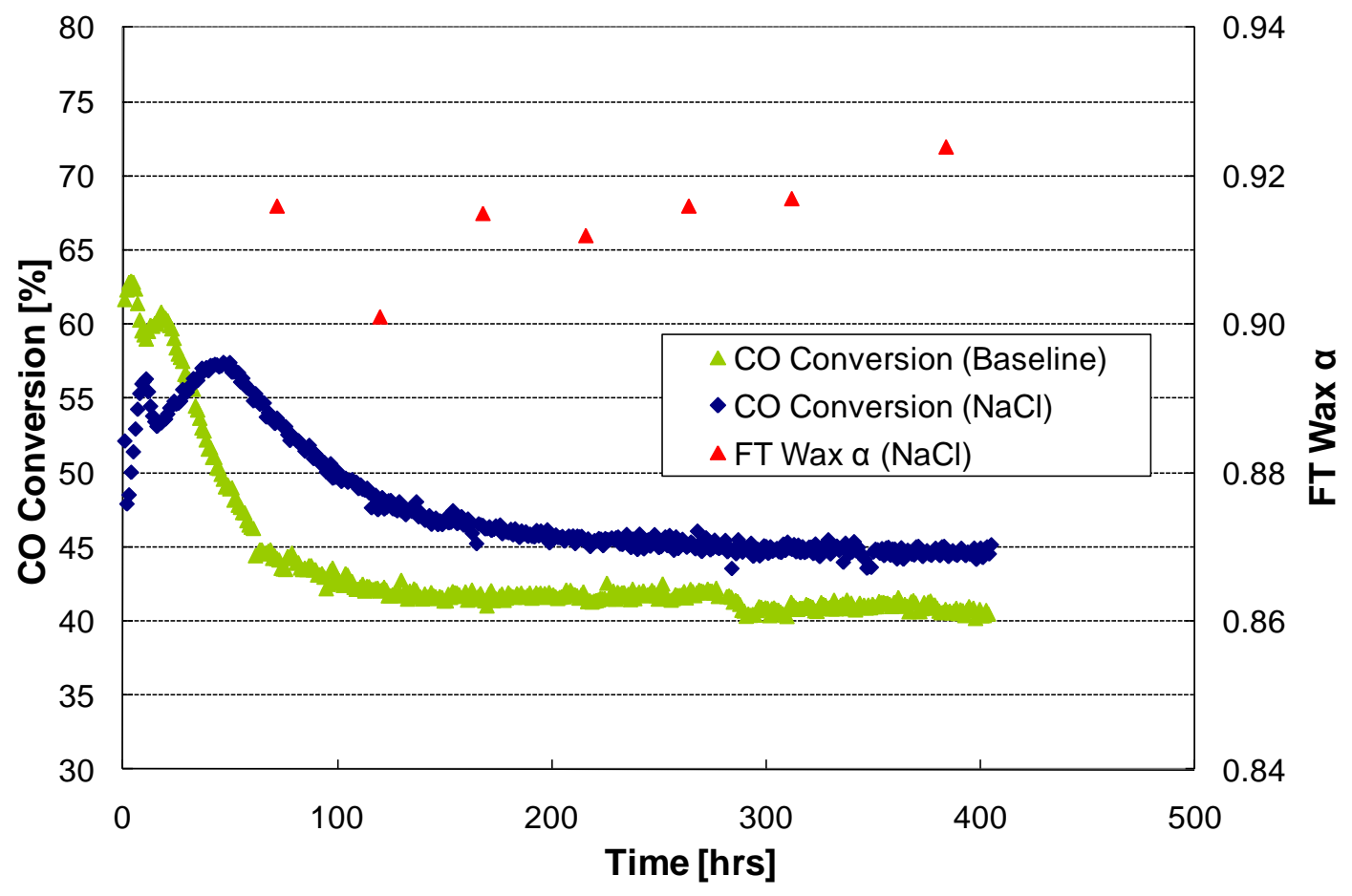

Figure 4-13. Effect of $\mathrm{NaCl}$ vapor on Fe-FT catalyst performance.

Table 4-10. Fe-FT Catalyst Performance Results in the Presence of NaCl Vapor

\begin{tabular}{|c|c|c|}
\hline \multirow{2}{*}{ Performance parameter } & \multicolumn{2}{|c|}{ NaCl vapor concentration (pptv) } \\
\hline & $\mathbf{0}$ & $2.2 \times 10^{-2}$ \\
\hline Exposure time [h] & 400 & 400 \\
\hline CO conversion [\%] & 41.6 & 44.2 \\
\hline $\begin{array}{l}\text { Catalyst productivity } \\
\text { [mg C }{ }_{5} / \mathrm{h} / \mathrm{g} \text { catalyst] }\end{array}$ & 158 & 162 \\
\hline $\mathrm{CH}_{4}$ selectivity [\%] & 2 & 2 \\
\hline $\mathrm{CO}_{2}$ selectivity [\%] & 33 & 33 \\
\hline FT wax $\alpha$ & $0.90-0.93$ & $0.90-0.93$ \\
\hline
\end{tabular}

\subsubsection{Exposure to KCI Vapor}

The $\mathrm{CO}$ conversion and FT wax $\alpha$ profiles for the Fe-FT catalyst exposed to syngas with $\mathrm{KCl}$ vapor are shown in Figure 4-14, and the average values for $\mathrm{CO}$ conversion, catalyst productivity, and $\mathrm{CH}_{4}$ and $\mathrm{CO}_{2}$ selectivities for the baseline syngas trial and syngas with $\mathrm{KCl}$ vapor contaminant are compared in Table 4-11. From these results, the Fe-FT catalyst performance is very similar in reaction conditions with and 
without $\mathrm{KCl}$ vapor. It can thus be concluded that $\mathrm{KCl}$ vapor does not adversely affect the Fe-FT catalyst performance.

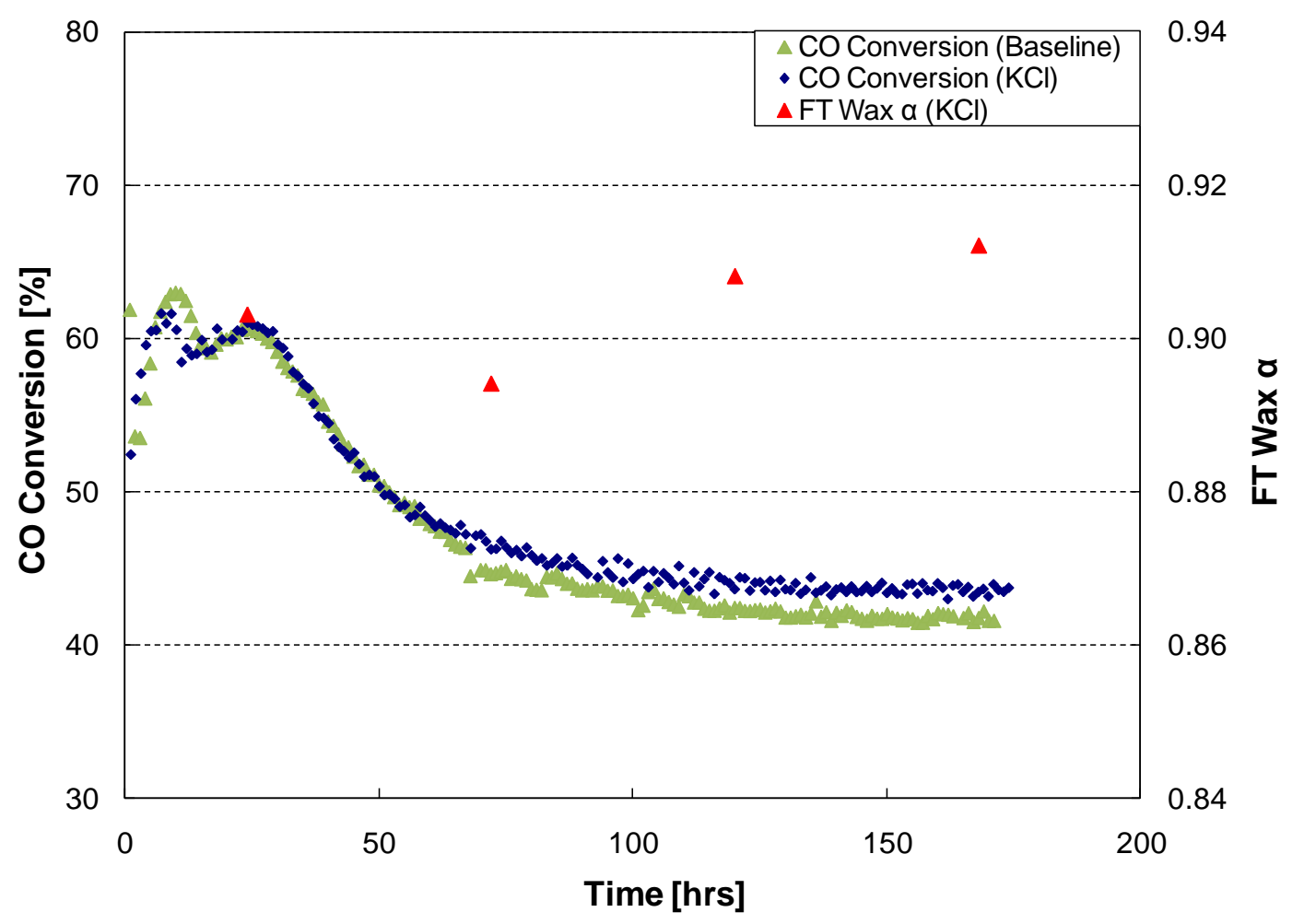

Figure 4-14. CO conversion and FT wax $\alpha$ of the Fe-FT catalyst with syngas containing $\mathrm{KCl}$ vapor.

Table 4-11. Fe-FT Catalyst Performance Results in the Presence of KCl Vapor

\begin{tabular}{|l|c|c|}
\hline \multirow{2}{*}{\multicolumn{1}{c|}{ Performance parameter }} & \multicolumn{2}{c|}{ KCl vapor concentration (pptv) } \\
\cline { 2 - 3 } & $\mathbf{0}$ & $\mathbf{7 . 9} \times \mathbf{1 0}^{-\mathbf{5}}$ \\
\hline Exposure time [h] & 150 & 150 \\
\hline CO conversion [\%] & 42 & 44 \\
\hline $\begin{array}{l}\text { Catalyst productivity } \\
\text { [mg C }\end{array}$, /h/g catalyst] & 162 & 164 \\
\hline $\mathbf{C H}_{\mathbf{4}}$ selectivity [\%] & 2 & 2 \\
\hline $\mathbf{C O}_{\mathbf{2}}$ selectivity [\%] & 33 & 33 \\
\hline FT wax $\boldsymbol{\alpha}$ & $0.90-0.93$ & $0.90-0.93$ \\
\hline
\end{tabular}

\subsubsection{Multi-contaminant Exposure}

In the multi-contaminant exposure study, the Fe-FT catalyst was tested with simulated CB-derived syngas mixtures containing $\mathrm{NaCl}, \mathrm{KCl}, \mathrm{NH}_{3}$, and $\mathrm{H}_{2} \mathrm{~S}$. The $\mathrm{CO}$ conversion and $\mathrm{FT}$ wax $\alpha$ profiles measured in the multi-contaminant study are compared with that obtained in the baseline syngas test in Figure 4-15. The average $\mathrm{CO}$ conversion, catalyst productivity, and $\mathrm{CH}_{4}$ and $\mathrm{CO}_{2}$ selectivities for each portion of the 
test trial are summarized in Table 4-12. A comparison of the rates of decline in CO conversion for the different contaminant combinations shows that this rate was statistically greatest for the ternary contaminant group containing $\mathrm{NaCl}, \mathrm{KCl}$, and $100 \mathrm{ppbv} \mathrm{H}_{2} \mathrm{~S}$, even when compared with that for the combination having all four contaminants $\left(\mathrm{NaCl}, \mathrm{KCl}, \mathrm{NH}_{3}\right.$, and $\left.\mathrm{H}_{2} \mathrm{~S}\right)$.

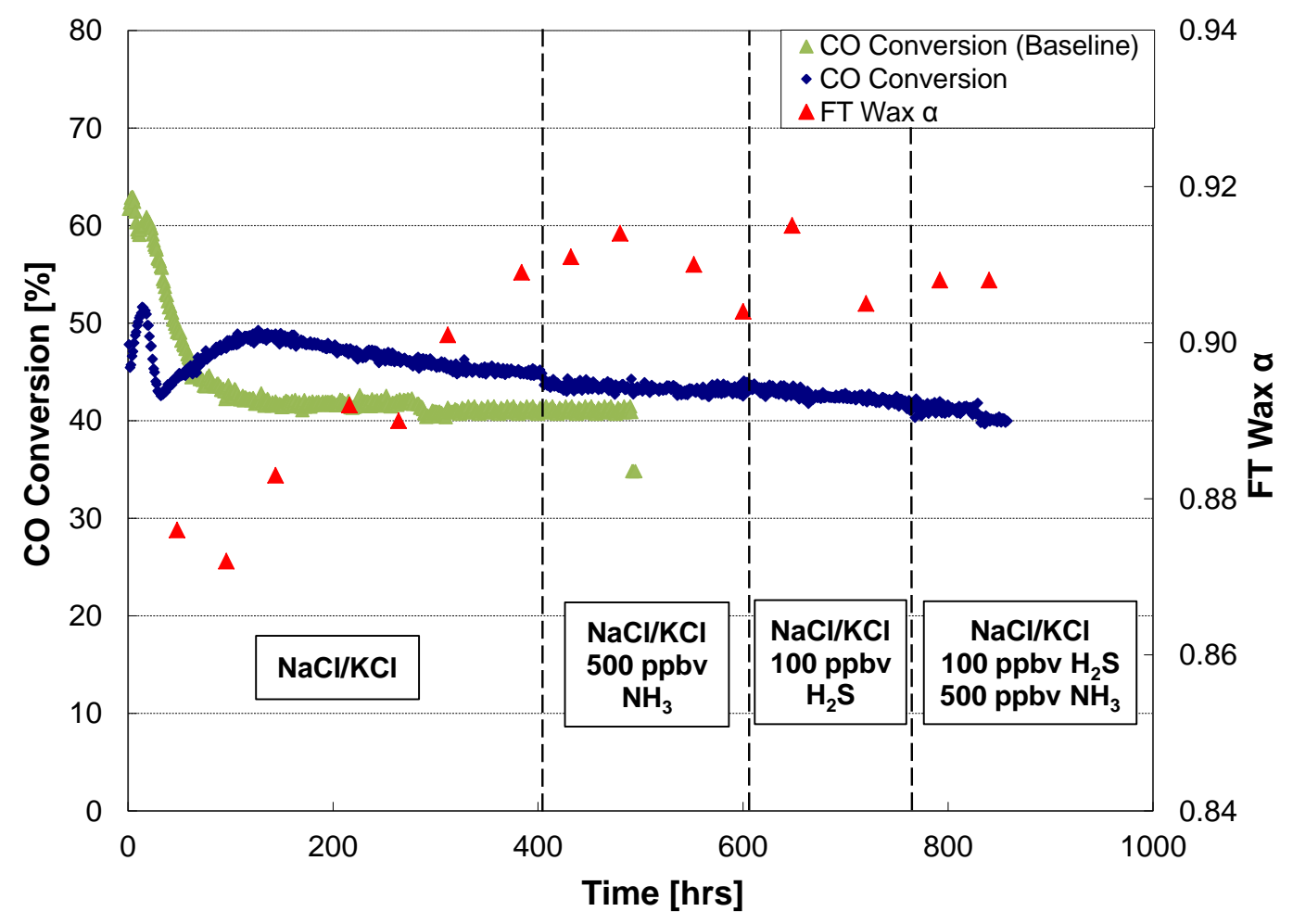

Figure 4-15. CO conversion and FT wax $\alpha$ of the Fe-FT catalyst with syngas containing multiple trace components.

Table 4-12. Fe-FT Catalyst Performance during Multi-contaminant Testing

\begin{tabular}{|c|c|c|c|c|}
\hline \multirow[b]{2}{*}{ Performance parameter } & \multicolumn{4}{|c|}{ Contaminant combination } \\
\hline & $\mathrm{NaCl}+\mathrm{KCl}$ & $\begin{array}{l}\mathrm{NaCl}+\mathrm{KCl}+ \\
500 \text { ppbv } \mathrm{NH}_{3}\end{array}$ & $\begin{array}{l}\mathrm{NaCl}+\mathrm{KCl}+ \\
100 \text { ppbv } \mathrm{H}_{2} \mathrm{~S}\end{array}$ & $\begin{array}{c}\mathrm{NaCl}+\mathrm{KCl}+500 \mathrm{ppbv}^{\mathrm{K} \mathrm{NH}_{3}}+ \\
100 \text { ppbv } \mathrm{H}_{2} \mathrm{~S}\end{array}$ \\
\hline Exposure time [h] & 250 & 200 & 160 & 80 \\
\hline CO conversion [\%] & 45 & 44 & 42 & 41 \\
\hline $\begin{array}{l}\text { Catalyst productivity } \\
{\left[\mathrm{mg} \mathrm{C}_{5} / \mathrm{h} / \text { g catalyst }\right]}\end{array}$ & 182 & 178 & 173 & 171 \\
\hline $\mathrm{CH}_{4}$ selectivity [\%] & 3 & 3 & 3 & 3 \\
\hline $\mathrm{CO}_{2}$ selectivity [\%] & 30 & 30 & 30 & 30 \\
\hline FT wax $\alpha$ & $0.90-0.93$ & $0.90-0.93$ & $0.90-0.93$ & $0.90-0.93$ \\
\hline
\end{tabular}

Note: Alkali vapor concentration $=2.2 \times 10^{-2} \mathrm{pptv}$ for $\mathrm{NaCl}$ and $7.9 \times 10^{-5} \mathrm{pptv}$ for $\mathrm{KCl}$ (see Table 4-2) 


\subsection{Co-FT Catalyst Test Results}

\subsubsection{Baseline Testing}

The CO conversion and FT wax $\alpha$ of the commercial Co-FT catalyst in baseline syngas is shown in Figure 4-16. After an initial period of decline, the CO conversion stabilized after 400 hours of operation. Based on these results, subsequent test trials were conducted by exposing the Co-FT catalyst to clean syngas for at least 400 hours to stabilize the catalyst activity before contaminant exposure was initiated.

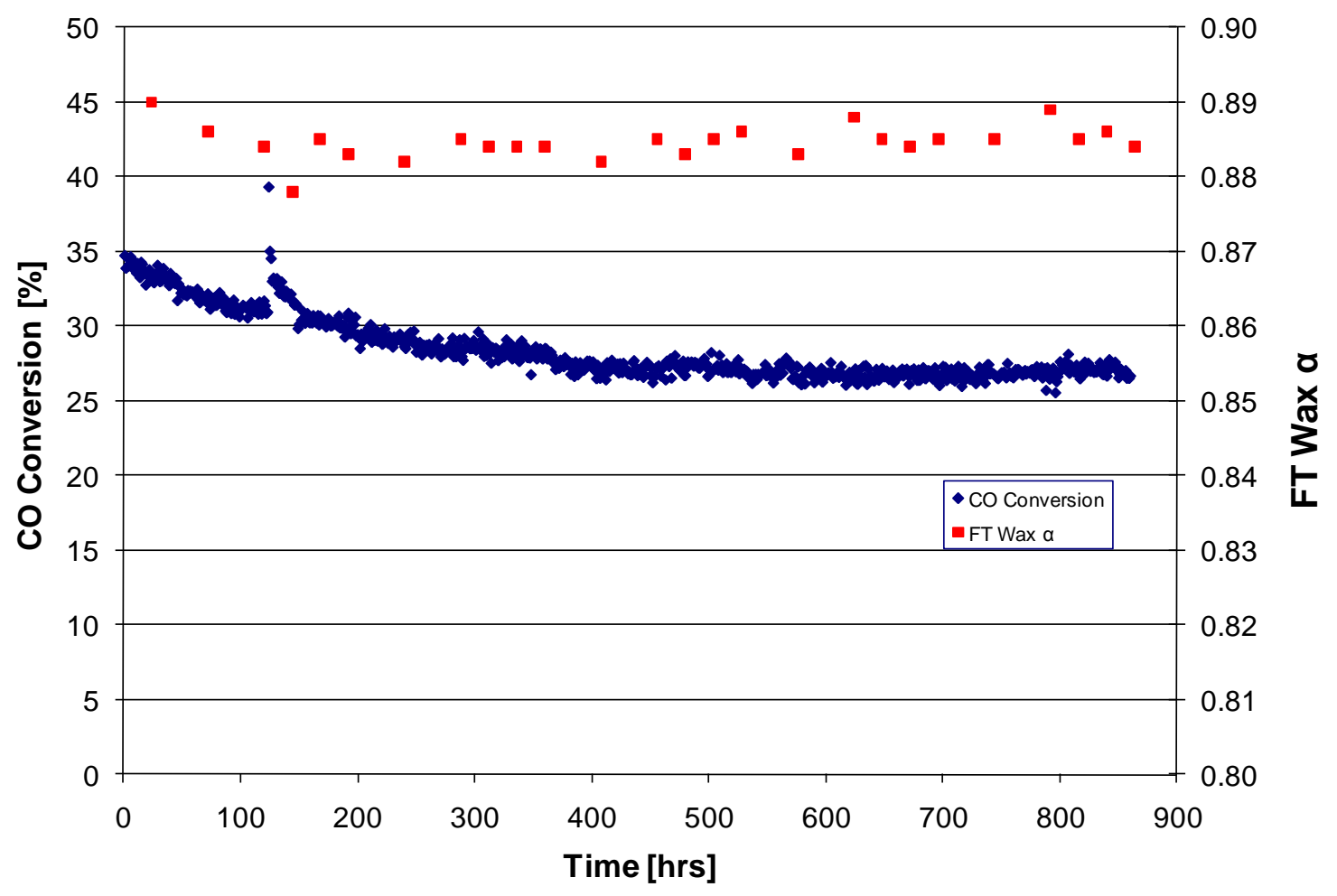

Figure 4-16. Baseline performance of the commercial Co-FT catalyst.

\subsubsection{Exposure to $\mathrm{H}_{\mathbf{2}} \mathrm{S}$}

After stabilizing its activity in clean syngas for $400 \mathrm{~h}$, the Co-FT catalyst was exposed to syngas having $10 \mathrm{ppbv} \mathrm{H}_{2} \mathrm{~S}$. The $\mathrm{CO}$ conversion and FT wax $\alpha$ profiles for this test are shown in Figure 4-17. After $400 \mathrm{~h}$, the $\mathrm{CO}$ conversion for the catalyst continued to steadily decline in the presence of $\mathrm{H}_{2} \mathrm{~S}$. This continual performance decline is more clearly seen when it is compared with the $\mathrm{CO}$ conversion profile obtained under baseline syngas conditions, which is also shown in Figure 4-17. Results from this trial demonstrate that the commercial Co-FT catalyst is extremely sensitive to even $10 \mathrm{ppbv}$ of $\mathrm{H}_{2} \mathrm{~S}$. 


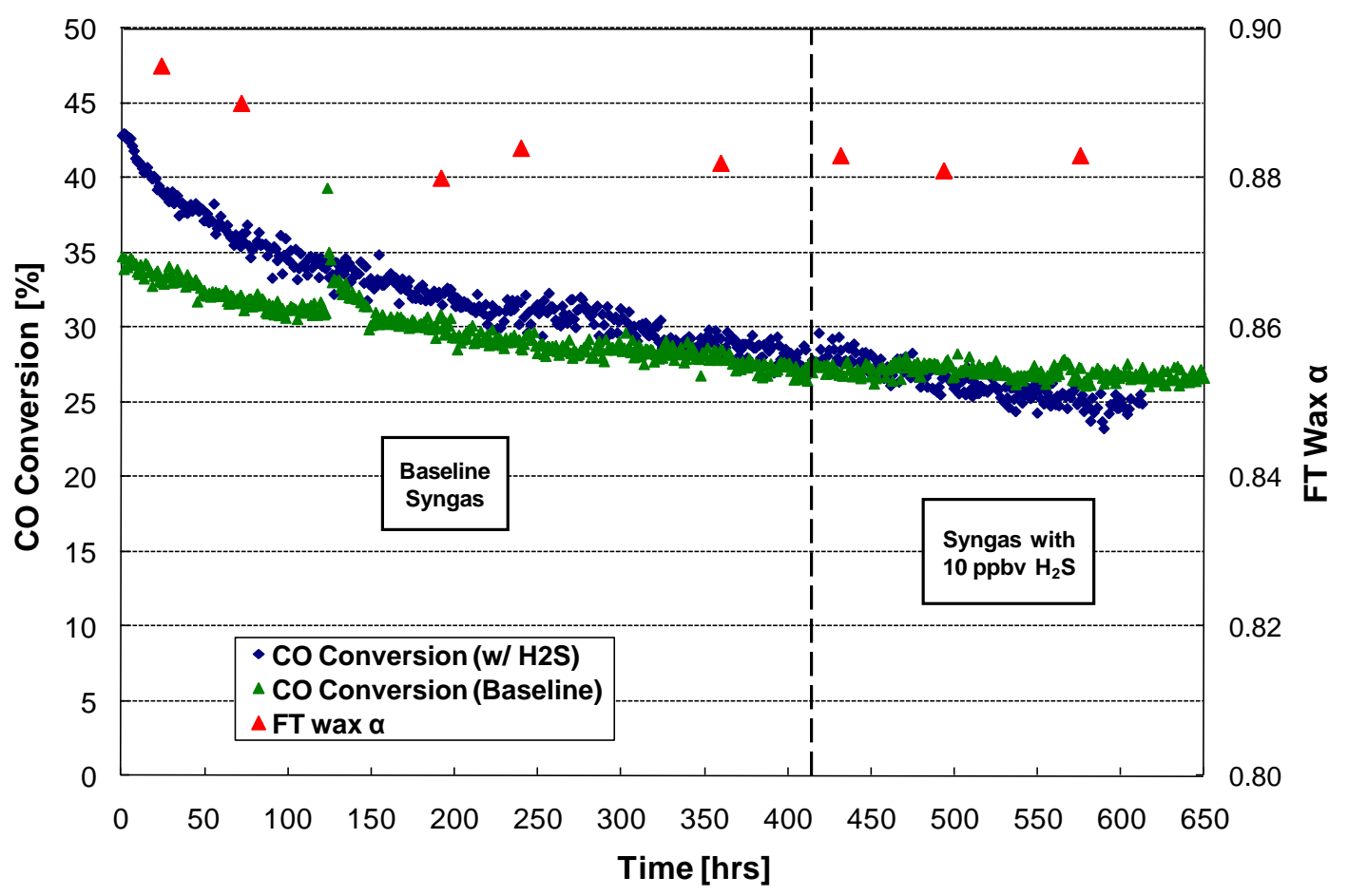

Figure 4-17. Co-FT catalyst performance in syngas with $10 \mathrm{ppbv} \mathrm{H}_{2} \mathrm{~S}$.

\subsubsection{Exposure to COS}

To evaluate the sensitivity of the Co-FT catalyst to COS, a single trial was completed with COS concentrations ranging from 10 to $100 \mathrm{ppbv}$. Figure 4-18 shows the $\mathrm{CO}$ conversion and FT wax $\alpha$ profiles for this trial, and Table 4-13 provides the average $\mathrm{CO}$ conversion, catalyst productivity, and $\mathrm{CH}_{4}$ and $\mathrm{CO}_{2}$ selectivities. Statistical comparison of the rate of change of $\mathrm{CO}$ conversion and catalyst productivity at COS concentrations of 10 and $40 \mathrm{ppbv}$ shows no significant difference relative to that observed in baseline syngas conditions. In contrast, exposure to $100 \mathrm{ppbv}$ COS significantly increased the rate of decrease in CO conversion and catalyst productivity. These data demonstrate that the Co-FT catalyst can perhaps tolerate COS concentrations below 40 ppbv but experiences a decline in $\mathrm{CO}$ conversion and catalyst productivity at COS concentrations above $100 \mathrm{ppbv}$. Furthermore, comparison of these exposure test results with those in Section 4.6.2 above clearly shows that $\mathrm{H}_{2} \mathrm{~S}$ is a stronger catalyst poison than COS. 


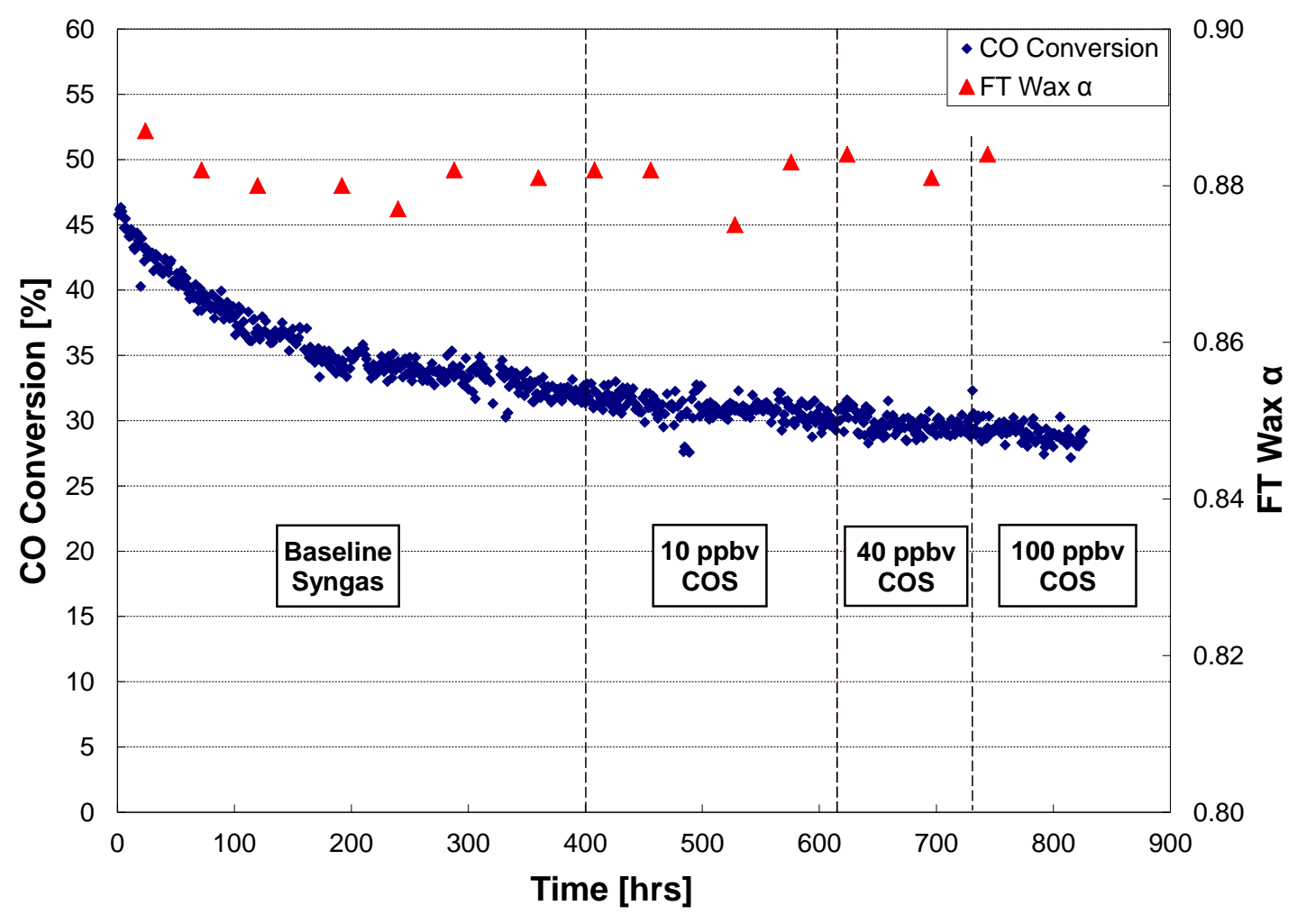

Figure 4-18. Co-FT catalyst performance with 10,40 , and 100 ppbv COS in syngas.

Table 4-13. Effect of COS Concentration on Co-FT Catalyst Performance

\begin{tabular}{|l|c|c|c|c|}
\hline \multirow{2}{*}{ Performance parameter } & \multicolumn{4}{c|}{ COS contaminant concentration (ppbv) } \\
\cline { 2 - 5 } & $\mathbf{0}$ & $\mathbf{1 0}$ & $\mathbf{4 0}$ & $\mathbf{1 0 0}$ \\
\hline Exposure time [h] & 400 & 200 & 100 & 100 \\
\hline CO conversion [\%] & 32 & 30 & 30 & 28 \\
\hline $\begin{array}{l}\text { Catalyst productivity } \\
\text { [mg } \mathbf{C}_{\mathbf{5}+\text { /h/g catalyst] }}\end{array}$ & 120 & 113 & 110 & 103 \\
\hline $\mathbf{C H}_{\mathbf{4}}$ selectivity [\%] & 13 & 14 & 14 & 14 \\
\hline $\mathbf{C O}_{\mathbf{2}}$ selectivity [\%] & 1 & 1 & 1 & 1 \\
\hline FT wax $\boldsymbol{\alpha}$ & $0.87-0.89$ & $0.87-0.89$ & $0.87-0.89$ & $0.87-0.89$ \\
\hline
\end{tabular}

\subsubsection{Exposure to $\mathrm{NH}_{3}$}

The effect of 100 to $1,000 \mathrm{ppbv}$ of $\mathrm{NH}_{3}$ on the Co-FT catalyst performance was evaluated in a single trial. The CO conversion and FT wax $\alpha$ profiles for this trial are shown in Figure 4-19, and average values of $\mathrm{CO}$ conversion, catalyst productivity, and $\mathrm{CH}_{4}$ and $\mathrm{CO}_{2}$ selectivities are provided in Table 4-14. A comparison of catalyst performance at the different $\mathrm{NH}_{3}$ concentrations indicates a decrease in catalyst productivity and CO conversion. Statistical analysis of the rate of change in CO conversion and catalyst

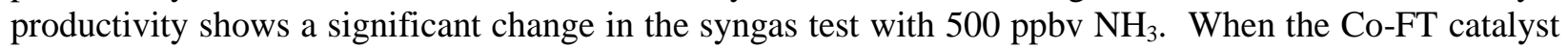


was exposed to $1,000 \mathrm{ppbv} \mathrm{NH}_{3}$ in the syngas, the catalyst productivity and $\mathrm{CO}$ conversion degraded even further by more than $20 \%$ relative to the baseline performance values.

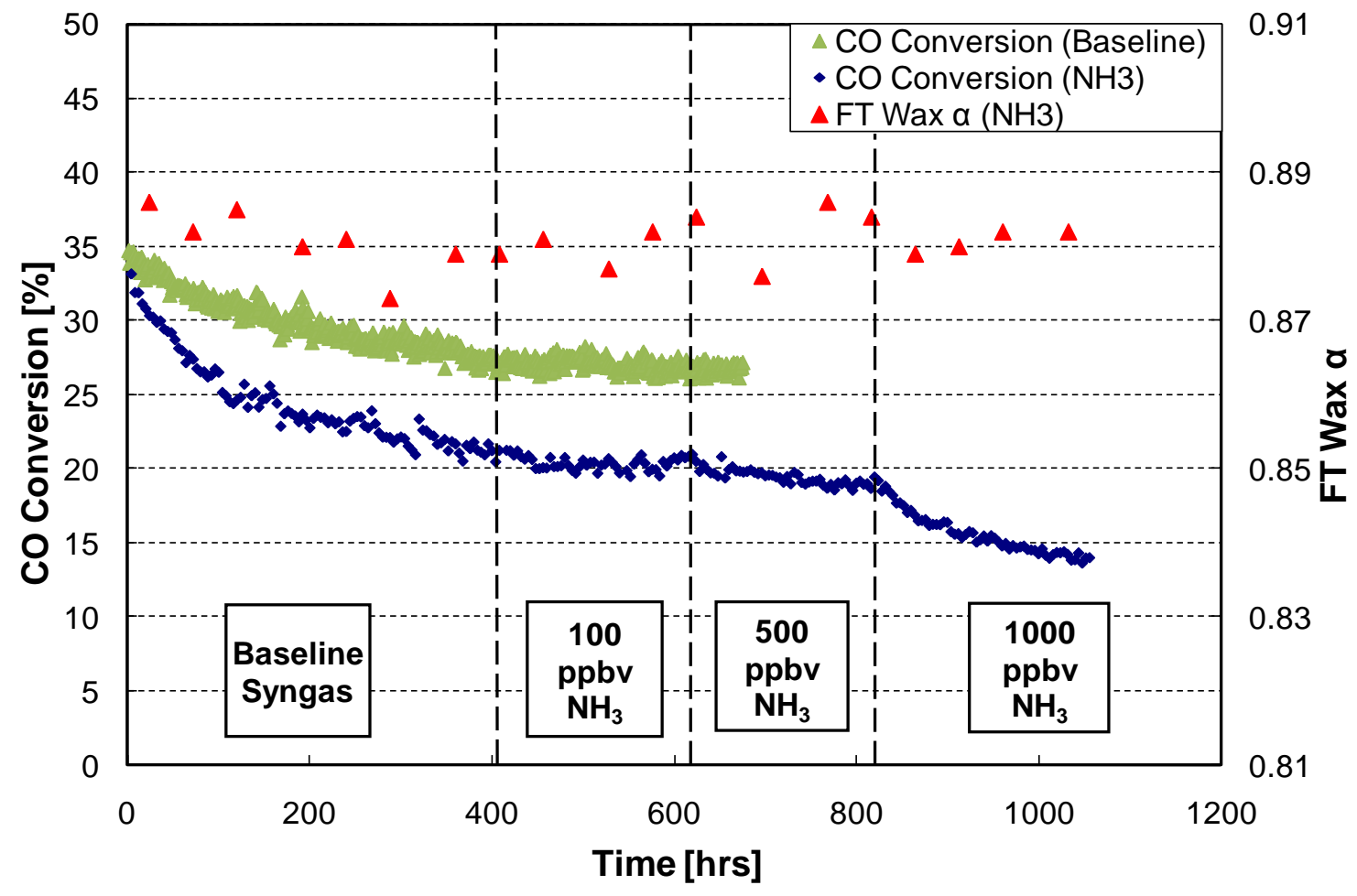

Figure 4-19. CO conversion and FT wax $\alpha$ for the Co-FT catalyst with syngas containing varying $\mathrm{NH}_{3}$ concentrations.

Table 4-14. Effect of $\mathrm{NH}_{3}$ Concentration on Co-FT Catalyst Performance

\begin{tabular}{|l|c|c|c|c|}
\hline \multirow{2}{*}{ Performance parameter } & \multicolumn{4}{|c|}{$\mathbf{N H}_{\mathbf{3}}$ contaminant concentration (ppbv) } \\
\cline { 2 - 5 } & $\mathbf{0}$ & $\mathbf{1 0 0}$ & $\mathbf{5 0 0}$ & $\mathbf{1 , 0 0 0}$ \\
\hline Exposure time [h] & 400 & 225 & 175 & 250 \\
\hline CO conversion [\%] & 21 & 21 & 19 & 14 \\
\hline $\begin{array}{l}\text { Catalyst productivity } \\
\text { [mg C }\end{array}$ /h/g catalyst] & 68 & 67 & 60 & 44 \\
\hline $\mathbf{C H}_{\mathbf{4}}$ selectivity [\%] & 19 & 19 & 20 & 23 \\
\hline $\mathbf{C O}_{\mathbf{2}}$ selectivity [\%] & 1 & 1 & 1 & 1 \\
\hline FT wax $\boldsymbol{\alpha}$ & $0.87-0.89$ & $0.87-0.89$ & $0.87-0.89$ & $0.87-0.89$ \\
\hline
\end{tabular}

\subsubsection{Exposure to NaCl Vapor}

The effect of $\mathrm{NaCl}$ vapor in syngas on the Co-FT catalyst performance was investigated for 500 hours. The CO conversion and FT wax $\alpha$ profiles for the catalyst in the presence of $\mathrm{NaCl}$ vapor are compared with that obtained in the baseline syngas test in Figure 4-20, and the average values for CO conversion, 
catalyst productivity, and $\mathrm{CH}_{4}$ and $\mathrm{CO}_{2}$ selectivities are presented in Table 4-15. From these results, the catalyst performances with and without the $\mathrm{NaCl}$ vapor contaminant are very similar. However, analysis of the rate of change in the $\mathrm{CO}$ conversion between the two trials demonstrates a statistically significant acceleration in the rate of decline in $\mathrm{CO}$ conversion for the case of syngas containing $\mathrm{NaCl}$ vapor.

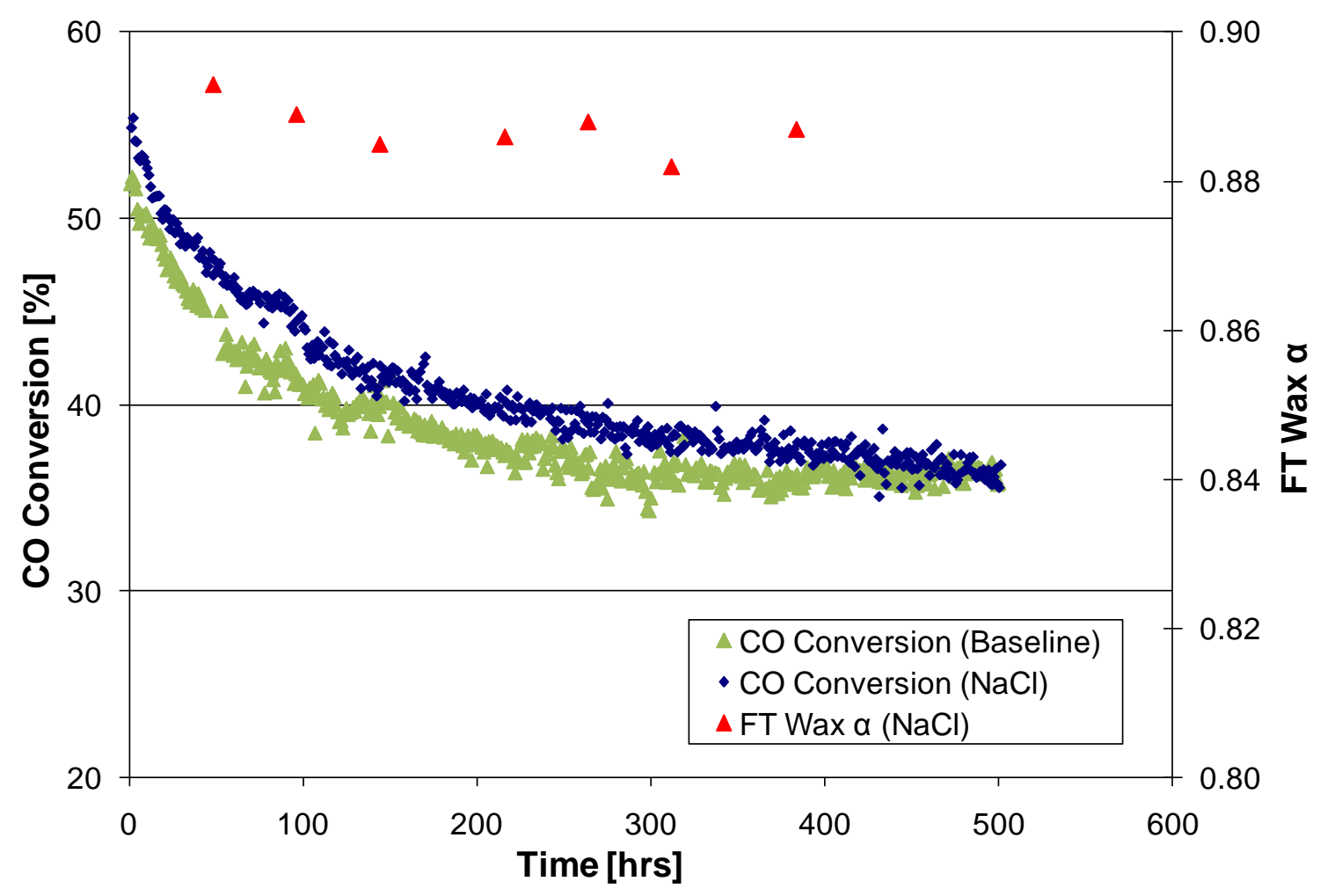

Figure 4-20. Effect of $\mathrm{NaCl}$ vapor in syngas on $\mathrm{CO}$ conversion and FT wax $\alpha$ of the Co-FT catalyst.

Table 4-15. Co-FT Catalyst Performance Results in the Presence of NaCl Vapor

\begin{tabular}{|c|c|c|}
\hline \multirow{2}{*}{ Performance parameter } & \multicolumn{2}{|c|}{ NaCl vapor concentration (pptv) } \\
\hline & $\mathbf{0}$ & $8.6 \times 10^{-4}$ \\
\hline Exposure time [h] & 500 & 500 \\
\hline CO conversion [\%] & 36 & 36 \\
\hline $\begin{array}{l}\text { Catalyst productivity } \\
\text { [mg C }{ }_{5} / \mathrm{h} / \mathrm{g} \text { catalyst] }\end{array}$ & 143 & 144 \\
\hline $\mathrm{CH}_{4}$ selectivity [\%] & 11 & 11 \\
\hline $\mathrm{CO}_{2}$ selectivity [\%] & 1 & 1 \\
\hline FT wax $\alpha$ & $0.87-0.89$ & $0.87-0.89$ \\
\hline
\end{tabular}

\subsubsection{Multi-contaminant Exposure}

In the multi-contaminant exposure study, the commercial Co-FT catalyst was exposed to simulated CB-derived syngas mixtures containing $\mathrm{NaCl}, \mathrm{KCl}, \mathrm{NH}_{3}$, and $\mathrm{H}_{2} \mathrm{~S}$. The measured $\mathrm{CO}$ conversion and FT 
wax $\alpha$ profiles are compared with that obtained in the baseline syngas test in Figure 4-21. The average $\mathrm{CO}$ conversion, catalyst productivity, and $\mathrm{CH}_{4}$ and $\mathrm{CO}_{2}$ selectivities for the different multi-contaminant combinations are provided in Table 4-16. The rate of decline in CO conversion at the completion of the initial exposure to both $\mathrm{NaCl}$ and $\mathrm{KCl}$ vapors was statistically similar to that previously seen for syngas containing only $\mathrm{NaCl}$ vapor, indicating that $\mathrm{KCl}$ vapor does not significantly affect the Co-FT catalyst performance. A comparison of the rates of decline in $\mathrm{CO}$ conversion for the different contaminant combinations shows that this rate was statistically greatest for the four-contaminant group consisting of $\mathrm{NaCl}, \mathrm{KCl}, 10 \mathrm{ppbv} \mathrm{H}_{2} \mathrm{~S}$, and 100 ppbv $\mathrm{NH}_{3}$.

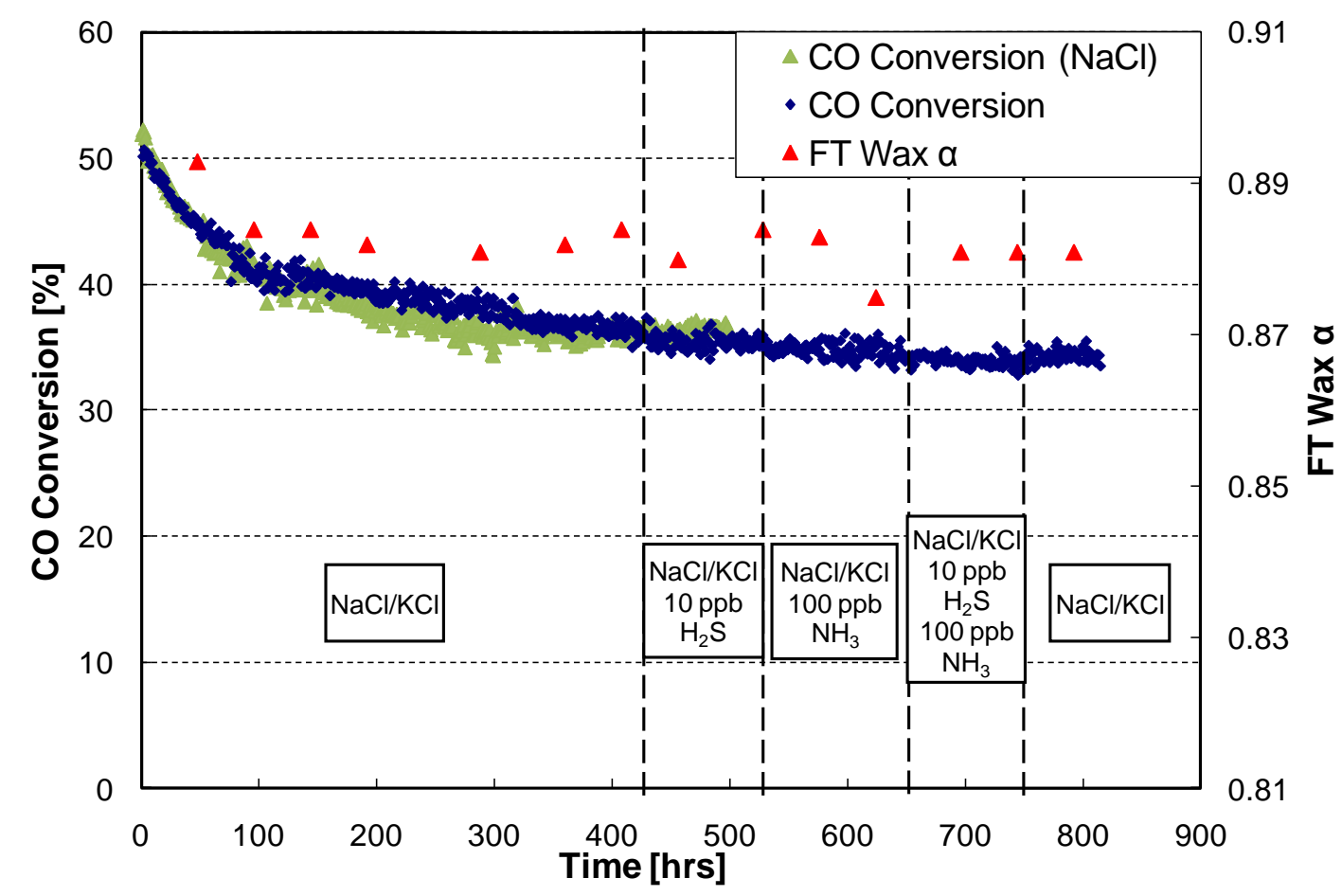

Figure 4-21. CO conversion and FT wax $\alpha$ of the Co-FT catalyst with syngas containing multicontaminants.

Table 4-16. Co-FT Catalyst Performance during Multi-contaminant Testing

\begin{tabular}{|c|c|c|c|c|c|}
\hline \multirow[b]{2}{*}{$\begin{array}{l}\text { Performance } \\
\text { parameter }\end{array}$} & \multicolumn{5}{|c|}{ Contaminant combination } \\
\hline & $\mathrm{NaCl}+\mathrm{KCl}$ & $\underset{10 \text { ppbv } \mathrm{H}_{2} \mathrm{~S}}{\mathrm{NaCl}+\mathrm{KCl}+}$ & $\begin{array}{l}\mathrm{NaCl}+\mathrm{KCl}+ \\
100 \text { ppbv } \mathrm{NH}_{3}\end{array}$ & $\begin{array}{l}\mathrm{NaCl}+\mathrm{KCl}+ \\
100 \text { ppbv } \mathrm{NH}_{3} \\
+10 \text { ppbv } \mathrm{H}_{2} \mathrm{~S}\end{array}$ & $\mathrm{NaCl}+\mathrm{KCl}$ \\
\hline Exposure time [h] & 30 & 100 & 120 & 100 & 65 \\
\hline CO conversion [\%] & 36 & 35 & 35 & 34 & 34 \\
\hline $\begin{array}{l}\text { Catalyst productivity } \\
\text { [mg C } \mathbf{C}_{5} / \mathrm{h} / \mathrm{g} \text { catalyst] }\end{array}$ & 144 & 141 & 138 & 135 & 136 \\
\hline $\mathrm{CH}_{4}$ selectivity [\%] & 11 & 11 & 11 & 11 & 11 \\
\hline $\mathrm{CO}_{2}$ selectivity [\%] & $0-1$ & $0-1$ & $0-1$ & $0-1$ & $0-1$ \\
\hline FT wax $\alpha$ & $0.87-0.89$ & $0.87-0.89$ & $0.87-0.89$ & $0.87-0.89$ & $0.87-0.89$ \\
\hline
\end{tabular}

Note: Alkali vapor concentration $=8.6 \times 10^{-4} \mathrm{pptv}$ for $\mathrm{NaCl}$ and $9.7 \times 10^{-7} \mathrm{pptv}$ for $\mathrm{KCl}$ (see Table $4-2$ ) 


\section{Conc/usions and Recommendations}

Significant accomplishments and major conclusions from the WGS and FT catalyst performance studies performed in this project are the following:

- Conducted a series of thermodynamic studies to determine potential of trace contaminants found in CB-derived syngas to react with commercial WGS and FT catalysts

- Designed, fabricated, and operated five highly automated, laboratory-scale microreactor systems to quickly and effectively acquire catalyst performance information

- Completed over 25,000 hours of cumulative operation in evaluating the effects of individual and multi-contaminant effects on commercial WGS and FT catalysts in simulated CB-derived syngas

The results from these exposure trials are summarized in Table 5-1.

Table 5-1. Summary of Results from Contaminant Exposure Trials

\begin{tabular}{|c|c|c|}
\hline \multirow[b]{2}{*}{ Catalyst } & \multicolumn{2}{|c|}{ Exposure trial } \\
\hline & Individual contaminants $^{1}$ & Multiple contaminants \\
\hline $\begin{array}{l}\text { LTS } \\
\text { (Low-temperature- } \\
\text { shift) }\end{array}$ & & $\begin{array}{l}\text { - No impact observed up to } 1,000 \mathrm{ppbv} \\
\text { of } \mathrm{NH}_{3} \text { and } \mathrm{H}_{2} \mathrm{~S}\end{array}$ \\
\hline $\begin{array}{l}\text { HTS } \\
\text { (High-temperature- } \\
\text { shift) }\end{array}$ & & $\begin{array}{l}\text { - Decline in } \mathrm{CO} \text { conversion demonstrated } \\
\text { for combinations of } \geq 150 \mathrm{ppbv} \mathrm{H}_{2} \mathrm{~S} \\
\text { and } 1,000 \mathrm{ppbv} \text { of } \mathrm{NH}_{3} \text { with alkali } \\
\text { vapors } \\
\text { - Alkali vapors did not result in } \mathrm{CO} \\
\text { conversion decline and potentially } \\
\text { resulted in recovery of lost } \mathrm{CO} \\
\text { conversion after exposure to } 1,000 \\
\text { ppbv } \mathrm{H}_{2} \mathrm{~S}\end{array}$ \\
\hline $\begin{array}{l}\text { SGS }^{2} \\
\text { (Sour-gas-shift) }\end{array}$ & & $\begin{array}{l}\text { - No impact observed up to } 1,000 \text { ppbv } \\
\mathrm{NH}_{3}\end{array}$ \\
\hline $\begin{array}{l}\text { Fe-FT } \\
\text { (Iron-based } \\
\text { Fischer-Tropsch) }\end{array}$ & $\begin{array}{l}\text { - } \mathrm{H}_{2} \mathrm{~S} \text { : Performance loss at }>150 \mathrm{ppbv} \\
\text { - } \mathrm{COS} \text { : Performance loss at }>175 \mathrm{ppbv} \\
\text { - } \mathrm{NaCl} \text { vapor: No impact } \\
\text { - } \mathrm{KCl} \text { vapor: No impact } \\
\text { - } \mathrm{NH}_{3} \text { : No impact }\end{array}$ & $\begin{array}{l}\text { - Most significant decrease in } \mathrm{CO} \\
\text { conversion observed with } \mathrm{NaCl}, \mathrm{KCl} \text {, } \\
\text { and } 100 \mathrm{ppbv} \mathrm{H}_{2} \mathrm{~S}\end{array}$ \\
\hline $\begin{array}{l}\text { Co-FT } \\
\text { (Cobalt-based } \\
\text { Fischer-Tropsch) }\end{array}$ & $\begin{array}{ll}\text { - } & \mathrm{H}_{2} \mathrm{~S} \text { : Performance loss at } 10 \mathrm{ppbv} \\
\text { - } & \mathrm{COS} \text { : Performance loss at }>100 \mathrm{ppbv} \\
\text { - } & \mathrm{NaCl} \text { vapor: No impact } \\
\text { - } & \mathrm{NH}_{3} \text { : Performance loss at }>1,000 \mathrm{ppbv}\end{array}$ & $\begin{array}{l}\text { - Statistically significant decrease in } \mathrm{CO} \\
\text { conversion observed with } \mathrm{NaCl}, \mathrm{KCl} \text {, } \\
10 \text { ppbv } \mathrm{H}_{2} \mathrm{~S} \text {, and } 100 \text { ppbv } \mathrm{NH}_{3}\end{array}$ \\
\hline
\end{tabular}

${ }^{1}$ Hatched regions indicate that individual contaminant exposure trials were not conducted with WGS catalysts.

${ }^{2}$ Multi-contaminant exposure trials were focused on alkali vapors and $\mathrm{NH}_{3}$.

At this time, no further exposure trials are planned. However, based on the thermodynamic analyses, individual and multi-contaminant exposure trials for $\mathrm{HCl}, \mathrm{AsH}_{3}, \mathrm{H}_{2} \mathrm{Se}, \mathrm{PH}_{3}$, and $\mathrm{Hg}$ are recommended for all WGS and FT catalysts. 